\title{
The SNMMI Practice Guideline for Therapy of Thyroid Disease with ${ }^{131}$ I 3.0*
}

Edward B. Silberstein ${ }^{1}$ (Chair), Abass Alavi ${ }^{2}$, Helena R. Balon ${ }^{3}$, Susan E.M. Clarke ${ }^{4}$, Chaitanya Divgi ${ }^{5}$, Michael J. Gelfand ${ }^{6}$, Stanley J. Goldsmith ${ }^{7}$, Hossein Jadvar ${ }^{8}$, Carol S. Marcus ${ }^{9}$, William H. Martin ${ }^{10}$, J. Anthony Parker ${ }^{11}$, Henry D. Royal ${ }^{12}$, Salil D. Sarkar ${ }^{13}$, Michael Stabin ${ }^{14}$, and Alan D. Waxman ${ }^{15}$

${ }^{1}$ UC Health University Hospital, Cincinnati, Ohio; ${ }^{2}$ Hospital of the University of Pennsylvania, Philadelphia, Pennsylvania; ${ }^{3}$ Beaumont Health System, Royal Oak, Michigan; ${ }^{4}$ Guy's Hospital, London, United Kingdom; ${ }^{5}$ Columbia University Medical Center, New York, New York; ${ }^{6}$ Cincinnati Children's Medical Center, Cincinnati, Ohio; ${ }^{7}$ New York-Presbyterian/Weill Cornell Medical Center, New York, New York; ${ }^{8}$ University of Southern California, Los Angeles, California; ${ }^{9}$ University of California at Los Angeles, Los Angeles, California; ${ }^{10}$ Vanderbilt University Medical Center, Nashville, Tennessee; ${ }^{11}$ Beth Israel Deaconess Medical Center, Boston, Massachusetts; ${ }^{12}$ Mallinckrodt Institute of Radiology, St. Louis, Missouri; ${ }^{13}$ Jacobi Medical Center, Bronx, New York; ${ }^{14}$ Vanderbilt University, Nashville, Tennessee; and ${ }^{15}$ Cedars-Sinai Medical Center, Los Angeles, California

\section{INDEX}

Preamble ....................... 1

I. Introduction: patient management, licensure. . . . 2

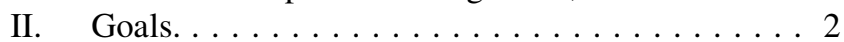

III. Definitions: risk levels. . . . . . . . . . . . . . 2

IV. Common clinical indications . . . . . . . . 3

V. Qualifications and responsibilities of personnel (in the United States). . . . . . . . . . . . . . . 3

VI. Procedure/specifications of the examination..... 4

A. Therapy of Graves disease, toxic nodules, and nontoxic nodular goiter . . . . . . . . . 4

1. Goals. . . . . . . . . . . . . . . . 4

2. Patient preparation: thionamides, consent form, $\operatorname{rhTSH}$ use. . . . . . . . . . 4

3. Information required by the physician performing the procedure; scintigraphy; pregnancy and lactation......... 5 5

4. Selection of administered activity. . . . . 6

5. Therapeutic procedure for administration of ${ }^{131} \mathrm{I} \ldots \ldots \ldots \ldots \ldots$

6. Follow-up. . . . . . . . . . . . . . 6

B. ${ }^{131}$ I therapy of thyroid cancer to ablate postthyroidectomy remnants and destroy residual or recurrent tumor. . . . . . . . . . . 7

1. Indications for treatment with ${ }^{131} \mathrm{I}$ : relationship to staging . . . . . . . . 7

2. Patient preparation and information the patient needs: diet, TSH level, informed consent, side effects. . . . . . . 8

Received Feb. 27, 2012; accepted Feb. 27, 2012.

For correspondence or reprints contact Edward B. Silberstein, Department of Nuclear Medicine, University of Cincinnati Medical Center, 234 Goodman

St., Room G026, Mont Reid Pavilion, Cincinnati, OH 45219.

E-mail: edward.silberstein@uchealth.com

*NOTE: YOU CAN ACCESS THIS GUIDELINE THROUGH THE SNMMI

WEBSITE (http://www.snmmi.org/guidelines).

Published online Jul. 11, 2012.

COPYRIGHT (C 2012 by the Society of Nuclear Medicine and Molecular Imaging, Inc.

DOI: $10.2967 /$ jnumed.112.105148
3. Information required by the physician performing the procedure: blood tests . . 10

4. Selection of activity. . . . . . . . . . 11

5. Therapeutic procedure for administration of ${ }^{131} \mathrm{I} \ldots \ldots \ldots \ldots 12$

6. Follow-up. . . . . . . . . . . . . . . 12

C. Radiation safety issues, patient discharge, home instructions . . . . . . . . . . 12

D. Interactions of ${ }^{131} \mathrm{I}$ with other forms of diagnosis or treatment . . . . . . . . . . . . 14

E. Radiopharmaceuticals. . . . . . . . . . . . . 15

F. Issues requiring further clarification. . . . . 15

VII. Documentation/reporting . . . . . . . . . . . 15

VIII. Equipment specification. . . . . . . . . . . 16

IX. Quality control and improvement .........16

X. Safety, infection control, and patient

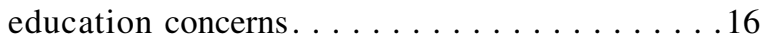

XI. Radiation dosimetry. . . . . . . . . . . . . . . . . . . . . .

XII. Acknowledgments. . . . . . . . . . . . . . . 16

XIII. References . . . . . . . . . . . . . . . . 16

XIV. Approval . . . . . . . . . . . . . . . . . . . 19

\section{PREAMBLE}

The Society of Nuclear Medicine and Molecular Imaging (SNMMI) is an international scientific and professional organization founded in 1954 to promote the science, technology, and practical application of nuclear medicine. Its 16,000 members are physicians, technologists, and scientists specializing in the research and practice of nuclear medicine. In addition to publishing journals, newsletters, and books, the SNMMI also sponsors international meetings and workshops designed to increase the competencies of nuclear medicine practitioners and to promote new advances in the science of nuclear medicine.

The SNMMI will periodically define new guidelines for nuclear medicine practice to help advance the science of nuclear medicine and to improve the quality of service to 
patients throughout the United States. Existing practice guidelines will be reviewed for revision or renewal, as appropriate, on their fifth anniversary or sooner, if indicated.

Each practice guideline, representing a policy statement by the SNMMI, has undergone a thorough consensus process in which it has been subjected to extensive review, requiring the approval of the Committee on Guidelines and SNMMI Board of Directors. The SNMMI recognizes that the safe and effective use of diagnostic nuclear medicine imaging requires specific training, skills, and techniques, as described in each document. Reproduction or modification of the published practice guideline by those entities not providing these services is not authorized.

These guidelines are an educational tool designed to assist practitioners in providing appropriate care for patients. They are not inflexible rules or requirements of practice and are not intended, nor should they be used, to establish a legal standard of care. For these reasons and those set forth below, the SNMMI cautions against the use of these guidelines in litigation in which the clinical decisions of a practitioner are called into question.

The ultimate judgment regarding the propriety of any specific procedure or course of action must be made by the physician or medical physicist in light of all the circumstances presented. Thus, there is no implication that an approach differing from the guidelines, standing alone, was below the standard of care. To the contrary, a conscientious practitioner may responsibly adopt a course of action different from that set forth in the guidelines when, in the reasonable judgment of the practitioner, such course of action is indicated by the condition of the patient, limitations of available resources, or advances in knowledge or technology subsequent to publication of the guidelines.

The practice of medicine involves not only the science, but also the art, of dealing with the prevention, diagnosis, alleviation, and treatment of disease. The variety and complexity of human conditions make it impossible to always reach the most appropriate diagnosis or to predict with certainty a particular response to treatment. Therefore, it should be recognized that adherence to these guidelines will not ensure an accurate diagnosis or a successful outcome. All that should be expected is that the practitioner will follow a reasonable course of action based on current knowledge, available resources, and the needs of the patient to deliver effective and safe medical care. The sole purpose of these guidelines is to assist practitioners in achieving this objective.

\section{INTRODUCTION}

Oral administration of ${ }^{131} \mathrm{I}$ has been a commonly accepted procedure for treatment of benign and malignant disorders of the thyroid since the 1940s. Physicians responsible for treating such patients should have an understanding of the clinical pathophysiology and natural history of the disease processes, should be familiar with alternative forms of therapy, and should be able to collaborate closely with other physicians involved in the management of the patient's condition. The treating physician should either see patients in consultation with the physician assuming overall management of the patient's condition or be prepared to assume that role. In the United States, the treating physician should be board-certified in nuclear medicine or be able to document equivalent training, competency, and experience in the safe use and administration of therapeutic ${ }^{131} \mathrm{I}$.

Licensure to possess ${ }^{131} \mathrm{I}$ and regulations regarding the release of patients treated with radioiodine vary from jurisdiction to jurisdiction. Physicians engaged in therapy with ${ }^{131}$ I must be knowledgeable about, and in compliance with, all applicable laws and regulations. The facility in which treatment is performed must have appropriate personnel, radiation safety equipment, and procedures available for waste handling and disposal, monitoring personnel for accidental contamination, and controlling spread of ${ }^{131} \mathrm{I}$ to conform to state and federal regulations. All physicians engaged in therapy have a duty to ensure that their knowledge and competencies are up to date.

\section{GOALS}

The purpose of this guideline is to assist trained practitioners in evaluating patients for therapy with ${ }^{131} \mathrm{I}$ (sodium iodide) for benign or malignant diseases of the thyroid gland, performing this treatment in a safe and appropriate manner, understanding and evaluating the sequelae of therapy, and reporting the results of therapy.

\section{DEFINITIONS}

See also the SNMMI Guideline for General Imaging.

${ }^{131} \mathrm{I}$ is a $\beta$-emitting radionuclide with a physical half-life of $8.1 \mathrm{~d}$; a principal $\gamma$-ray of $364 \mathrm{keV}$; and a principal $\beta$-particle with a maximum energy of $0.61 \mathrm{MeV}$, an average energy of $0.192 \mathrm{MeV}$, and a mean range in tissue of $0.4 \mathrm{~mm}$ $(1,2)$. Therapy means the oral administration of ${ }^{131} \mathrm{I}$ as sodium iodide to treat papillary and follicular thyroid cancer, hyperthyroidism, or nontoxic nodular goiter, in contrast to the diagnostic use of radioiodine to detect functioning thyroid tissue. Benign diseases include Graves disease (toxic diffuse goiter) and toxic or nontoxic nodular goiter. Malignant diseases in this guideline indicate papillary and follicular types of thyroid cancer that are sufficiently differentiated to be able to synthesize thyroglobulin and, in most cases, accumulate radioiodine. Ablation refers to the use of ${ }^{131}$ I to eliminate residual normal thyroid tissue detected after thyroidectomy.

The risk to the thyroid cancer patient of recurrence and death varies from very low to high $(3,4)$. Classifying the prognosis for the risk of recurrence and dying from thyroid cancer has also been performed by the American Joint Committee on Cancer (AJCC), in detailed stages I-IV (5). The following systems of risk evaluation are similar to one another but not identical, indicating our lack of precise long-term outcome data for all the variables. They remain 
valuable for prognostic purposes and in considering therapeutic options.

\section{A. Very low risk}

The very-low-risk category excludes cancers with high-risk histopathology (e.g., tall cell, insular, columnar, diffuse sclerosing, trabecular, solid, poorly differentiated papillary carcinoma, and the Hürthle cell variant of follicular carcinoma) and cancers with vascular invasion (3).

In patients under the age of $45 \mathrm{y}$, this category includes unifocal or multicentric microcarcinoma $(<1.0 \mathrm{~cm})$, tumors smaller than $4 \mathrm{~cm}$ confined to the thyroid (3) (tumors $>1.0 \mathrm{~cm}$ are seen by some as more risky (6)), a stage I variation from AJCC (T12 N0 M0) (2), and tumors with a MACIS (metastases, age, completeness of resection, invasiveness, and size) score of less than 6 (7). In patients over the age of 45 $\mathrm{y}$, this category includes unifocal or multicentric microcarcinomas, a stage I variation from AJCC (T1-2 N0 M0) (3), and tumors with a MACIS score of less than $6(7)$.

\section{B. Low risk}

There are 2 definitions for the low-risk category $(3,4)$.

According to Sacks et al. (3), in patients under the age of $45 \mathrm{y}$ this category includes tumors smaller than $4 \mathrm{~cm}$ with or without microscopic central-compartment lymph node metastases but no distant metastases (3); a stage I variation from AJCC (T1-T2 N0-N1a M0) (3); AJCC stage I (any T any N M0) (5); tumors with a MACIS score of less than 6 (7). In patients over the age of $45 \mathrm{y}$ this category includes tumors smaller than $4 \mathrm{~cm}$ confined to the thyroid with no node involvement (3) (i.e., AJCC stage II [T2 N0 M0] (5)) and tumors with a MACIS score of less than 6 (7).

According to Cooper et al. (4), patients are in the low-risk category if they have no local or distant metastases after thyroidectomy and remnant ablation, if all macroscopic tumor was resected, and if there is no tumor invasion of locoregional tissues or structures, no aggressive histology, no vascular invasion, and, if ${ }^{131} \mathrm{I}$ is given, no ${ }^{131}$ I uptake outside the thyroid bed on the posttreatment whole-body scan.

\section{Moderate risk}

There are 2 definitions for the moderate-risk category $(3,4)$.

According to Sacks et al. (3), in patients under the age of $45 \mathrm{y}$ this category includes tumors larger than 4 $\mathrm{cm}$; macroscopic $(>1 \mathrm{~cm})$ central-compartment or lateral lymph node metastases; an aggressive histologic type; a minimally invasive (i.e., microscopic capsular, but not vascular, invasion) follicular carcinoma smaller than $4 \mathrm{~cm}$ (minimally invasive follicular carcinoma is seen by some as low risk) (3); a stage I variation from AJCC (T1-3 N1b M0) (3); and tumors with a MACIS score of more than 6 (7). In patients over the age of $45 \mathrm{y}$ this category includes tumors with an aggressive histologic type (as listed above), with a minimally (i.e., microscopic) invasive follicular carcinoma smaller than $4 \mathrm{~cm}$ (3), with AJCC stage III (T3 N0 M0 or T1-T3 N1a M0) (5)), or with a MACIS score of more than 6 (7).

According to Cooper et al. (4), patients are in the intermediate-risk category if they have microscopic invasion of tumor into the perithyroidal soft tissues at initial surgery or a tumor with aggressive histology or vascular invasion.

\section{High risk}

Patients under the age of $45 \mathrm{y}$ are in the high-risk category if they have distant metastases; extension to muscle; invasion of prevertebral fascia, subcutaneous soft tissues, the larynx, the trachea, the esophagus, or recurrent laryngeal nerve; encasement of the carotid artery or mediastinal vessels; a stage I variation from AJCC (T4a or T4b any N M0) (3); AJCC stage II (any T any N M1) (5); or a MACIS score of more than 6 (7).

Patient over the age of $45 \mathrm{y}$ are in the high-risk category if they have tumor extension to muscle; invasion of subcutaneous soft tissues, the larynx, the trachea, the esophagus, or recurrent laryngeal nerve; invasion of prevertebral fascia or encasement of the carotid artery or mediastinal vessels; central- or lateral-compartment lymph node metastases; distant metastases; macroscopic invasive follicular carcinoma or a follicular carcinoma larger than $4 \mathrm{~cm} \mathrm{(3);} \mathrm{AJCC}$ stage IVA (T4a any N M0 or T1-T3 N1b M0), IVB (T4b any $\mathrm{N}$ M0), or IVC (any T any N M1) (5); or a MACIS score of more than 6 (7).

\section{COMMON CLINICAL INDICATIONS}

Common indications for therapy of thyroid diseases with ${ }^{131}$ I include, but are not limited to, benign diseases such as certain types of hyperthyroidism $\left({ }^{131} \mathrm{I}\right.$ may be indicated for the treatment of Graves disease and toxic nodular [uninodular or multinodular] disease (8)) and nontoxic nodular goiter ( ${ }^{131}$ I therapy may be used successfully to diminish the size of nontoxic nodular goiters, especially when surgery is contraindicated or refused $(9,10))$, and differentiated papillary and follicular thyroid cancer $\left({ }^{131} \mathrm{I}\right.$ therapy is the principal treatment of residual thyroid tissue after thyroidectomy [thyroid remnant ablation], of residual or recurrent thyroid cancer, and of metastatic disease after near-total thyroidectomy).

\section{QUALIFICATIONS AND RESPONSIBILITIES OF PERSONNEL (IN THE UNITED STATES)}

See also the SNMMI Guideline for General Imaging.

The SNMMI believes that training and experience according to the nuclear medicine program requirements of the 


\begin{tabular}{ll}
\hline \multicolumn{1}{c}{ Type of medication } & Recommended time of withdrawal \\
\hline $\begin{array}{l}\text { Thionamide medications (e.g., propylthiouracil, } \\
\text { methimazole carbimazole) }\end{array}$ & $3 \mathrm{~d}$ \\
\hline Multivitamins containing iodide & $7-10 \mathrm{~d}$ \\
Natural or synthetic thyroid hormones & $10-14 \mathrm{~d}$ for triiodothyronine \\
& $3-4 \mathrm{wk}$ for thyroxine \\
Kelp, agar, carrageenan, Lugol solution & $2-3 \mathrm{wk}$, depending on iodide content \\
Saturated solution of potassium iodide & $2-3 \mathrm{wk}$ \\
Topical iodine (e.g., surgical skin preparation) & $2-3 \mathrm{wk}$ \\
Intravenous radiographic contrast agents & \\
$\quad$ Water soluble & $6-8$ wk, assuming normal renal function \\
$\quad$ Lipophilic & $1-6$ mo \\
Amiodarone & $3-6$ mo or longer (100) \\
\hline
\end{tabular}

Accreditation Council for Graduate Medical Education (11), or the equivalent, are necessary for physicians to provide appropriate and effective therapy with unsealed radiopharmaceuticals. These requirements go beyond those of the U.S. Nuclear Regulatory Commission (NRC) for authorized users, which provide only for the safe handling and delivery of radiopharmaceuticals. The minimum requirements for supervision and administration of radiopharmaceuticals (12) include the supervised, independent evaluation and treatment with ${ }^{131} \mathrm{I}$ of a minimum of 10 patients for hyperthyroidism and a minimum of 5 patients for thyroid carcinoma.

\section{PROCEDURE/SPECIFICATIONS OF THE EXAMINATION}

See also the SNMMI Guideline for General Imaging.

\section{A. Therapy of Graves disease, toxic nodules, and nontoxic nodular goiter}

1. Goals

The goal of therapy for hyperthyroidism is to achieve a nonhyperthyroid status - either a euthyroid state or iatrogenic hypothyroidism that has been completely compensated to the euthyroid state with oral levothyroxine. The goal of therapy for a large nontoxic nodular goiter is the reduction of thyroid volume to relieve symptoms caused by compression of the goiter on structures in the neck.

\section{Patient preparation}

For a sufficient time before therapy, patients must discontinue use of iodide-containing medications and preparations that could potentially affect the ability of thyroid tissue to accumulate iodide (Table 1).

Pretreatment of selected patients with thionamides (methimazole [Tapazole; Eli Lilly and Co.] or propylthiouracil) to deplete thyroid hormone stores may be helpful, although there must be awareness of uncommon adverse reactions to thionamides, including agranulocytosis and hepatotox- icity (13). ${ }^{131}$ I therapy can cause radiation-induced thyroiditis with release of stored thyroid hormone into the circulation, resulting in occasional transient worsening of hyperthyroidism and, rarely, precipitation of thyroid storm. This is more likely to occur in patients with a large, iodine-avid thyroid gland who are given higher activities of ${ }^{131} \mathrm{I}$. Accordingly, elderly patients and patients with significant preexisting heart disease, severe systemic illness, or debility may benefit from pretreatment with thionamides. The thionamide should be discontinued for $3-5 \mathrm{~d}$ before the radioiodine therapy is given and can be resumed 2-3 d afterward. Some experts recommend administering a higher activity of ${ }^{131} \mathrm{I}$ in patients who have been pretreated with a thionamide. Although some studies suggest that radioresistance is more likely with propylthiouracil than methimazole, the issue remains unsettled $(14,15)$. A randomized study found no effect of pretreatment of Graves disease with methimazole on outcome (16). In another study, thionamides had no effect on the outcome of Graves disease, but the outcome of radioiodine therapy for toxic nodular goiter was adversely affected. Large goiters and severe hyperthyroidism may also be associated with radioresistance and require a higher ${ }^{131} \mathrm{I}$ administered activity (15). Other groups of patients for whom a higher activity $(\mathrm{kBq}[\mu \mathrm{Ci}] / \mathrm{g})$ has been recommended include pediatric patients and patients with rapid turnover, such as when the radioiodine uptake at $4 \mathrm{~h}$ exceeds that at $24 \mathrm{~h}$. Treatment with $\beta$-blockers can be helpful for symptomatic control. $\beta$-blockers need not be discontinued before treatment with ${ }^{131} \mathrm{I}$.

The treating physician must explain the procedure, treatment, complications, side effects, therapeutic alternatives, and expected outcome to the patient. Written information must be provided to the patient according to the NRC (17). The treating physician should obtain written informed consent before therapy. The consent form should include 
several items specific to the therapy of hyperthyroidism. The form should state that more than one ${ }^{131}$ I treatment may be necessary and that long-term follow-up is necessary, that recurrent laryngeal nerve palsy and dysgeusia (altered or distorted sense of taste) are very uncommon side effects, and that there is a small $(1 \%-5 \%)$ chance of a mildly painful radiation thyroiditis after treatment but that acetaminophen or other nonnarcotic analgesic therapy usually suffices and corticosteroids are rarely required. The form should also explain that the likelihood of eventual hypothyroidism is high in Graves disease and somewhat lower with nodular goiters. It can occur within the first few months after therapy or even decades later, with a small, ongoing annual incidence. Lifelong thyroid hormone supplementation would then become necessary.

Other information to be included on the consent form is that ophthalmopathy may worsen or develop after ${ }^{131}$ I therapy for Graves' disease, especially in smokers. High levels of pretreatment serum triiodothyronine, posttherapy hypothyroidism, and thyroid-stimulating hormone (TSH) receptor antibody are also associated with an increased risk of the development or progression of ophthalmopathy (18). In addition, the form should state that patients with severe hyperthyroidism may occasionally experience an exacerbation of symptoms within the first $2 \mathrm{wk}$ after ${ }^{131} \mathrm{I}$ therapy. These symptoms usually respond to short-term $\beta$-blocker therapy and a thionamide but rarely may progress to frank thyroid storm. Patients should be instructed to seek immediate medical care should such symptoms occur. The consent form should also mention that, on the basis of previous multicenter trials, there is no evidence of an increased risk of thyroid carcinoma or other malignancy, an increased risk of infertility, or an increased incidence of birth defects caused by ${ }^{131} \mathrm{I}$ therapy for hyperthyroidism. There does exist a small risk of preexisting or coexisting thyroid cancer in patients with toxic nodular goiter and Graves disease unrelated to ${ }^{131}$ I therapy $(19,20)$. A final item to consider including on the informed consent form is that most experts recommend waiting 6-12 mo after ${ }^{131}$ I therapy before trying to conceive a child (although there are no scientific data on the subject).

The patient's ability to comply with the prescribed radiation precautions should be ascertained, and travel precautions should be reviewed and a card or letter documenting the therapy should be provided to the patient.

Recombinant human TSH (rhTSH; Thyrogen [Genzyme Corp.]) has been used (in an off-label use) in patients with nontoxic or toxic nodular goiter with low iodine uptake to maximize thyroid gland uptake and minimize the radiation dose to the rest of the body. An effective rhTSH dose to stimulate uptake and not increase circulating thyroid hormone has been reported as $0.03 \mathrm{mg}$ given once or twice $(21,22)$.

3. Information required by the physician performing the procedure

The treating physician should obtain the patient's thyroid-related medical history and perform a directed physical examination. The cumulative administered activity of ${ }^{131} \mathrm{I}$ should be reviewed and entered in the patient's record. The patient's identity must be confirmed in accordance with institutional policy before administration of ${ }^{131} \mathrm{I}$. For patients with a history of renal disease or diabetes, renal function should be assessed. Peritoneal or hemodialysis is not a contraindication to ${ }^{131} \mathrm{I}$ therapy (32), and dosimetry should be helpful to determine the maximum tolerated dose.

The results from recent measurements of thyroid hormone levels (free T4, total or free T3) and TSH should be available and reviewed. The avidity of the thyroid gland for iodide must be established. This should be accomplished quantitatively using a recent radioiodine uptake measurement with ${ }^{123} \mathrm{I}$ or ${ }^{131} \mathrm{I}$, combined with a thyroid scan (especially in the presence of a nodule) or a stimulating TSH receptor antibody study, either of which usually can distinguish between Graves disease, a toxic multinodular goiter, and a uninodular adenoma. These procedures will also differentiate silent thyroiditis and thyrotoxicosis factitia from other forms of hyperthyroidism. If radioiodine is unavailable for scintigraphy, ${ }^{99 \mathrm{~m}} \mathrm{Tc}$-pertechnetate is an option and ${ }^{99 \mathrm{~m}} \mathrm{Tc}$ uptake can be determined quantitatively $(23,24)$, although the correlation of ${ }^{99 \mathrm{~m}} \mathrm{Tc}$-pertechnetate uptake with ${ }^{123}$ I uptake is not perfect since the former is not organified. In the presence of an elevated level of anti-TSH receptor antibody, orbitopathy, and pretibial myxedema, a thyroid scan may be unnecessary, and an uptake measurement with 185-370 $\mathrm{kBq}(5-10 \mu \mathrm{Ci})$ of ${ }^{131} \mathrm{I}$ may suffice. Ultrasonography generally does not contribute to the differential diagnosis of thyrotoxicosis (25).

${ }^{131}$ I therapy is always contraindicated in pregnant women. The fetal thyroid gland concentrates iodine by weeks 10-13 (26). Female patients who have the potential to be pregnant must always be tested for pregnancy using a urine or serum $\beta$-human chorionic gonadotropin (hCG) test, ideally within $24 \mathrm{~h}$ of treatment, as the pregnancy test may remain negative for up to 7-10 d after fertilization (27). The urine $\beta$-hCG test can rarely detect 
hormone levels less than 20-25 mIU/mL, whereas serum testing is sensitive to $10 \mathrm{mIU} / \mathrm{mL}$ or lower. Caution is therefore advised in treating patients who have had unprotected intercourse in the $10 \mathrm{~d}$ before treatment, and the treating physician should consider discussing the limitation of the pregnancy test with the patient, which could include consideration of delaying the therapy until the beginning of the next cycle.

Before omitting a pregnancy test in women of childbearing age, some institutions may require written historical confirmation of hysterectomy (a pregnancy test is still required in some institutions despite a history of tubal ligation). In some cases in which the patient has declared that pregnancy is impossible and the $\beta$-hCG test is consequently omitted, the patient has in fact been pregnant $(27,28)$. If inadvertent administration of ${ }^{131} \mathrm{I}$ to a pregnant patient does occur, information on counseling patients about the significance of accidental administrations of ${ }^{131} \mathrm{I}$ is available from the patient's obstetrician and a reference provided at the end of this guideline (29).

All potentially breastfeeding or lactating women must be asked if they are lactating. If so, they must be advised to stop breastfeeding, and therapy must be delayed until lactation ceases, in order to minimize the radiation dose to the breast (30). Lactation (and the ability of the breast to concentrate large amounts of iodine) usually ceases 4-6 wk after birth (with no breastfeeding) or 4-6 wk after breastfeeding stops. Documentation in the patient's record that the patient denies breastfeeding is suggested. If there is uncertainty as to whether the previously lactating breasts still concentrate iodine, this may be assessed by noting the absence of uptake on pretherapy scintigraphy $(28,31)$ with ${ }^{123} \mathrm{I}$ or ${ }^{99} \mathrm{~m}$ Tc-pertechnetate. Several approaches are available to speed the cessation of lactation, but these are beyond the scope of this guideline. The patient may not resume breastfeeding for that child. Nursing may resume with the birth of another child.

If the patient's mental status prevents the signing of an informed consent form, a guardian or close family member can sign the form and should be present during ${ }^{131} \mathrm{I}$ therapy. Some patients with cognitive impairment may not be able to tolerate admission and isolation in a hospital or to follow instructions necessary to allow the patient to be treated at home with ${ }^{131} \mathrm{I}$. Treatment in these cases must be carefully individualized. With incontinence, diapering the patient and bagging the contaminated material may be necessary, but waste disposal must be done in cooperation with relevant local authorities so as not to set off alarms at waste facilities.
4. Selection of administered activity

A variety of methods has been used to select the amount of administered activity (33-35). The thyroid radiation dose depends on the radioiodine uptake measurement, gland size, and biologic half-life of the radioiodine in the thyroid gland, which can vary widely. Although it is reasonable to base ${ }^{131} \mathrm{I}$ activity on the radiation dose delivered to the thyroid gland rather than administered activity, there are few publications documenting or confirming this unequivocally $(34,36)$. Dosimetry for the ${ }^{131}$ I treatment of thyrotoxicosis has not been standardized.

One nondosimetric method is to use the estimated thyroid gland size and the results of a 24-h radioiodine uptake measurement to calculate the therapeutic activity of ${ }^{131} \mathrm{I}$ in order to achieve a desired concentration of ${ }^{131} \mathrm{I}$ in the thyroid gland. A delivered activity of 3-8 MBq (80-220 $\mu \mathrm{Ci}) / \mathrm{g}$ of thyroid tissue has been used $(15,16,37,38)$, although $3 \mathrm{MBq} / \mathrm{g}$ is rather low to have an acceptable cure rate if correctable hypothyroidism is the goal. Although some treating physicians choose to aim for a euthyroid state using an activity toward the lower end of this range, decreasing the administered therapeutic activity in an effort to achieve a euthyroid state can lead to prolongation of hyperthyroidism with adverse clinical sequelae. The ${ }^{131} \mathrm{I}$ activity used in children in $\mathrm{MBq} / \mathrm{g}$ of thyroid tissue is similar to that used in adults.

An administered ${ }^{131} \mathrm{I}$ activity toward the upper end of this range or even higher is especially suitable for patients with nodular goiters, very large toxic diffuse goiters, and repeated therapies (8), as well as for patients with rapid iodine turnover, such as when 4-h iodine uptake exceeds 24-h uptake.

Empiric rather than calculated dosage strategies are also used for Graves disease, toxic multinodular goiter, and solitary toxic nodules. For example, 550 $\mathrm{MBq}(15 \mathrm{mCi})$ may be used for the usual-size solitary nodule ( $\sim 1.5-3 \mathrm{~cm}$ in diameter) and higher doses for larger nodules $(37,38)$. The same approach could be applied to therapy of diffuse toxic goiter or Graves disease depending on the size and activity of the gland.

5. Therapeutic procedure for administration of ${ }^{131} \mathrm{I}$

The procedure for administration of ${ }^{131} \mathrm{I}$ for Graves disease, toxic nodules, and nontoxic nodular goiter is the same as described below for ${ }^{131}$ I therapy of thyroid cancer.

6. Follow-up

The treated thyrotoxic patient must be closely followed, as ${ }^{131}$ I-induced hypothyroidism may occur within 2-3 mo of therapy. Levothyroxine replacement therapy should be started when TSH elevation is detected and should have as its goal a euthyroid, symptom-free state. Many experts consider hypothyroidism after a single dose of ${ }^{131} \mathrm{I}$ a desired 
outcome of ${ }^{131}$ I therapy because it avoids frequent office visits and laboratory testing to detect the late onset of hypothyroidism and decreases the risk of untreated, persistent, or recurrent hyperthyroidism. These patients should be followed for many years to maintain the euthyroid state.

The patient treated for compressive symptoms for an enlarged nontoxic goiter should be followed closely, as swelling of the gland may worsen symptoms and signs.

\section{B. ${ }^{131}$ I therapy of thyroid cancer to ablate postthyroidectomy remnants and destroy residual or recurrent tumor}

1. Indications for treatment with ${ }^{131} \mathrm{I}$ : relationship to staging

${ }^{131}$ I ablative or tumoricidal treatment of differentiated thyroid cancer with radioiodine should be considered in the postsurgical management of patients with a maximum tumor diameter greater than $1.0 \mathrm{~cm}$ or with a maximum tumor diameter less than $1.0 \mathrm{~cm}$ in the presence of high-risk features such as aggressive histology (Hürthle cell, insular, diffuse sclerosing, tall cell, columnar cell, trabecular, solid, and poorly differentiated subtypes of papillary carcinoma), lymphatic or vascular invasion, lymph node or distant metastases, multifocal disease, capsular invasion or penetration, perithyroidal soft-tissue involvement (39-42), or an elevated antithyroglobulin antibody level after thyroidectomy (so that scintigraphy can be used for surveillance).

The treatment of very low and low-risk thyroid cancers with ${ }^{131} \mathrm{I}$ is controversial, as most data suggest no statistically significant improvements in disease-specific survival, although the recurrence rates may decrease $(3,43)$.

Because treatment choices depend, among other factors, on the pathology, location, and size of thyroid cancer, preablation staging must be considered. The presence or absence of iodine-accumulating thyroid tissue before ablation should be documented by uptake measurement and imaging (see SNMMI Guideline for Scintigraphy for Differentiated Thyroid Cancer).

Routine preablation planar scintigraphy can be useful in guiding ${ }^{131} \mathrm{I}$ therapy. A small minority of patients will need no ${ }^{131} \mathrm{I}$ ablative therapy because there is no remnant or because an area that seemed to concentrate iodine was a physiologic variant such as thymus, dental inflammation, or asymmetric salivary gland uptake (44). Other patients may have too much residual tissue to be able to receive ${ }^{131}$ I safely, as the risk of symptomatic radiation thyroiditis becomes significant. A completion thyroidectomy may be required in such cases.

The preablation scan may alter staging when thyroid cancer is present and hence change the activity of therapeutic ${ }^{131}$ I to be administered. SPECT/CT now has the capability of distinguishing thyroid remnants from regional nodal metastases. Distant metastases in the lung, bone, or brain may be detected on planar imaging and more accurately localized with SPECT/CT, not only causing a reevaluation of the use or dosage of ${ }^{131}$ I (4547 ) but also, with brain metastases, bringing about consideration of whether corticosteroid administration is required $(48,49)$. Some experts believe this happens too infrequently to justify the time and cost of routine SPECT/CT required for preablation scanning, raising the as yet unanswered question of whether routine preablation SPECT/CT will increase the rates of both complete remission and survival. Those centers that do not perform preablation scans also raise concerns that the diagnostic administered activity of ${ }^{131}$ I may possibly stun the thyroid remnant, causing lower uptake of the therapeutic dosage of ${ }^{131} \mathrm{I}$ in subsequent ablative therapy. The likelihood and clinical relevance of stunning with low-activity (37-111 MBq [1-3 $\mathrm{mCi}]$ ) diagnostic imaging is also controversial. Some investigators feel that the therapeutic ${ }^{131}$ I activity given within $3 \mathrm{~d}$ after the diagnostic activity reduces the probability of stunning. Others see the reported decrease in uptake of therapeutic ${ }^{131} \mathrm{I}$ activity after the administration of a low diagnostic activity of ${ }^{131}$ I as caused by the cytocidal effect of the latter. A randomized study of preablation imaging with $14.8 \mathrm{MBq}(0.4 \mathrm{mCi})$ of ${ }^{123} \mathrm{I}$ versus $74 \mathrm{MBq}$ ( $2 \mathrm{mCi})$ of ${ }^{131} \mathrm{I}$ showed no difference in the ablation rate $(81 \%$ vs. $74 \%, P>0.05)(50)$. Since ${ }^{123}$ I produces Auger electrons and at least one report of ${ }^{123} \mathrm{I}$ stunning exists (albeit to a lesser degree than with $\left.{ }^{131} \mathrm{I}\right)(51)$, it is possible that both activities of these radiopharmaceuticals cause stunning, but the ablation rates from both are comparable to those in the literature. Studies of patients receiving 111- to 185$\mathrm{MBq}$ (3-5 $\mathrm{mCi}$ ) doses of ${ }^{131} \mathrm{I}$ versus no ${ }^{131} \mathrm{I}$ preablation diagnostic scintigraphy also showed no differences in percentage ablation: $65 \%$ for scanned patients and $67 \%$ for unscanned patients (52).

Further staging studies should be used depending on the level of risk of the cancer, as defined above, and on any specific clinical suspicion of metastatic disease. If metastatic disease in the cervical lymph nodes is suspected, ultrasonography (for preoperative staging and biopsy) is less expensive and more widely used than MRI or CT but is operator-dependent; there do not appear to be documented differences in sensitivity. Low-risk cancers may simply need a baseline ultrasound examination of the neck postoperatively. If lung metastases are suspected, CT (without contrast medium) is far more sensitive than chest radiography; 
MRI is not recommended. If bone metastases are suspected, especially in the presence of musculoskeletal symptoms, preablative therapy ${ }^{99 \mathrm{~m}} \mathrm{Tc}-$ bisphosphonate (diphosphonate) bone scans or bone radiographs are needed (bone scan, 75\%$78 \%$ sensitive) $(53,54) ;{ }^{18} \mathrm{~F}$-fluoride bone PET/CT may be more sensitive than ${ }^{99 \mathrm{~m}} \mathrm{Tc}$-bisphosphonate (diphosphonate) skeletal imaging (55).

${ }^{18}$ F-FDG PET may be helpful in detecting metastases when used in follow-up imaging if the radioiodine study is negative and the serum thyroglobulin is rising or elevated. The presence of ${ }^{18}$ F-FDG-avid disease, especially high-volume ${ }^{18} \mathrm{~F}-\mathrm{FDG}$-avid disease, indicates a relatively poor prognosis compared with patients with no ${ }^{18} \mathrm{~F}-\mathrm{FDG}$ uptake in viable tumor $(56,57) .{ }^{124} \mathrm{I}$ PET/CT has a higher spatial resolution and image contrast than planar imaging or SPECT with ${ }^{131} \mathrm{I}$ but has yet to be shown to make a clinical impact (58). ${ }^{124}$ I may have a role in improving lesion dosimetry (59). However, ${ }^{124} \mathrm{I}$ is approved by the Food and Drug Administration only for investigational use at this time.

Postthyroidectomy ${ }^{131} \mathrm{I}$ therapy is indicated for metastases of functioning thyroid carcinoma to lymph nodes, lung, bone, and, less often, brain, liver, skin, and other sites.

2. Patient preparation and information the patient needs

A state of iodine deficiency should be induced to increase ${ }^{131} \mathrm{I}$ uptake. For a sufficient time before the contemplated therapy, patients must discontinue use of iodide-containing preparations and other medications that could potentially affect the ability of the thyroid tissue to accumulate iodide. Watersoluble iodinated contrast medium should not have been administered for at least 6-8 wk (Table 1).

Most experts recommend a low-iodine diet for 7$14 \mathrm{~d}$ before administration of therapy, in order to increase radioiodine uptake and improve the ablation rate $(60)$. Institutions should develop written instructions to assist patients in complying with the low-iodine diet (61). Although the 24-h urinary iodine excretion is not routinely measured in most institutions, this information can be useful if patient compliance with the low-iodine diet is uncertain, if there has been administration of amiodarone within a year or iodinated contrast agents within 2-3 mo, or if there is concurrent renal insufficiency. Urinary iodine should optimally be below $50 \mu \mathrm{g} / 24 \mathrm{~h}$ (60). Pharmaceuticals blocking iodine uptake are listed in Table 1. A list of foods containing a significant amount of iodine appears in Table 2 and on the Thyroid Cancer Survivors Association Web site (62). Because there are no studies on whether resuming a normal diet 24,48 , or $72 \mathrm{~h}$ after ${ }^{131} \mathrm{I}$ therapy yields any difference in ablation or successful therapy rates, no data-based recommendation can be provided.

It must be emphasized to the patient that this is not a low-salt or low-sodium diet but a low-iodine diet $(50 \mu \mathrm{g} / \mathrm{d})$ and that noniodized salt is allowed and widely available. Red dye 40 (Food, Drug, and Cosmetic [FD\&C] Act dye 40), an azo dye, is iodine-free. FD\&C red dyes 3 and 28 contain up to 8 atoms of iodine per molecule and must be excluded from any low-iodine diet. Thyroid hormone contains iodine, and some clinicians stop thyroid hormones for about $4 \mathrm{~d}$ before administration of ${ }^{131} \mathrm{I}$ therapy if rhTSH is used. This period will not induce a hypothyroid state. Outcome studies on this approach are unavailable, and the half-life of thyroxine, about $7 \mathrm{~d}$ in a euthyroid patient, makes this recommendation of uncertain value. The use of a diuretic to reduce body iodine content is not advised because of the side effects of hypokalemia and hypotension and because furosemide causes a decrease in urinary iodide excretion and higher blood concentration (63).

The serum TSH should exceed about $30 \mu \mathrm{IU} / \mathrm{mL}$ to maximize ${ }^{131} \mathrm{I}$ uptake. The data to support 30

TABLE 2

Dietary Sources of Significant Amounts of lodine

Source

lodized salt

Dairy products

Egg yolks

Seafood

Turkey and liver

Seaweed and kelp products

Commercial bread

Milk chocolate

lodide-containing multivitamins

FD\&C red dyes 3 and 28

Grains

Soy proteins
Examples/comments

Milk, yogurt, cheese, ice cream

Not egg whites or egg substitutes

Crustaceans and fish, except tuna

Carrageenan, alginate

When made with iodide conditioners
Small portions only, e.g., one fourth of a plate Goitrogens in humans so fortified with iodine (101) 
$\mu \mathrm{IU} / \mathrm{mL}$ as a number representing the threshold of optimal stimulation is more a matter of consensus than the result of detailed scientific study (64). This may be achieved in 1 of 2 ways. First, thyroid hormones may be withheld for a time sufficient to permit an adequate rise in TSH $(>30 \mu \mathrm{IU} / \mathrm{mL})$. This is at least $10-14 \mathrm{~d}$ for triiodothyronine (T3) and usually 3 wk for thyroxine (T4) (61). TSH may not rise to this level if a large volume of functioning tissue remains or if hypopituitarism is present. Second, thyrotropin- $\alpha$ (rhTSH) may be used. The manufacturer's suggested dosage of rhTSH is $0.9 \mathrm{mg}$ injected intramuscularly in the buttock on 2 consecutive days. In data on file with the Food and Drug Administration, the manufacturer, Genzyme Corp., has shown a $148-\mathrm{MBq}(4 \mathrm{mCi}){ }^{131} \mathrm{I}$ dose for the whole-body scan to be more effective than lower activities in the diagnostic use of rhTSH after thyroidectomy. rhTSH is approved in the United States and Europe for use in diagnostic testing and for ablation of thyroid remnants (65-67). Randomized double-blind prospective studies showing the equivalence of rhTSH and thyroid hormone withdrawal for the successful therapy of distant metastatic disease have not been published, but a retrospective study has indicated similar 5-y survival in thyroid cancer patients with distant metastatic disease prepared for ${ }^{131} \mathrm{I}$ therapy with either thyroid hormone withdrawal or rhTSH (68). Data on follow-up of such patients for longer than $5 \mathrm{y}$ have not yet been published as of early 2012. The use of rhTSH requires a larger therapeutic activity of ${ }^{131} \mathrm{I}$ than thyroid hormone withdrawal, and the helpfulness of dosimetric studies in this area has been suggested. Whole-body radiation exposure is less than that after thyroid hormone withdrawal for an equal administered activity of ${ }^{131} \mathrm{I}$ because of the preservation of glomerular filtration rate in the euthyroid state.

The treating physician must explain the diet, preparatory procedures, treatment, potential side effects, therapeutic alternatives, radiation precautions, and probability of expected outcome to the patient or the patient's representative. Written material containing this information should be provided to the patient or the patient's representative (17).

The treating physician must obtain signed informed consent before therapy, and the consent form should include items specific to the therapy of thyroid cancer and also should include possible adverse reactions. Information about posttherapy actions to reduce or prevent adverse reactions may be incorporated into the consent form or be placed on a separate patient information form. The consent from should state that the purpose of ablative treatment is to destroy remnants of normal thy- roid tissue and presumed remaining cancerous thyroid tissue. Other normal tissues may also be affected. More than one ${ }^{131}$ I treatment may be necessary. Early side effects may include oral mucositis, nausea, occasional vomiting, sialadenitis, loss of taste, or unusual, often metal-like, alterations in taste. Painful thyroiditis is more likely to occur if there is a sizeable postsurgical remnant present and may be associated with neck swelling, impingement on the trachea, and, rarely, recurrent laryngeal nerve paralysis. There is no significant literature that documents the incidence, complications, and severity of radiation thyroiditis after ${ }^{131}$ I therapy for large fragments.

To address sialadenitis, measures should be taken to maintain a high level of hydration and, possibly, stimulate salivary flow after therapy by administration of a sialagogue (e.g., sugar-free candy, pilocarpine, and ascorbic acid), and consideration may be given to administering dexamethasone or amifostine. These efforts have, however, shown mixed results in preventing swollen, painful salivary glands $(69,70)$. A regimen involving the constant use of candy and gum beginning $2 \mathrm{~h}$ after ${ }^{131}$ I therapy during waking hours and every 3 h for 4 nights after treatment, plus $4 \mathrm{~d}$ of an oral serotonin 5-hydroxytryptamine receptor 3 receptor antagonist and dexamethasone every 8-12 h, has eliminated acute radiation sialadenitis in a series (71), contradicting a report about lemon candy increasing the salivary radiation dose and symptoms (72). This observation needs to be duplicated.

Nausea and, rarely, vomiting may occur about 2$8 \mathrm{~h}$ after ${ }^{131} \mathrm{I}$ administration and resolve within 24 $72 \mathrm{~h}$. Vomiting can be prevented by prophylactic administration of oral antiemetics, including phenothiazines or selective serotonin 5-hydroxytryptamine receptor 3 antagonists. Corticosteroids have been successfully used to potentiate the antiemetic effect of these drugs when high dosages of ${ }^{131} \mathrm{I}$ are used.

Neck pain and swelling can occur if a sizeable thyroid remnant remains after surgery, especially when the postoperative, preablative ${ }^{123} \mathrm{I}$, or ${ }^{131} \mathrm{I}$ uptake is found to be close to the reference range.

With ${ }^{131} \mathrm{I}$ activity in excess of 5.55-7.4 GBq (150-200 mCi), a transient decrease in white blood cell and platelet counts may occur for up to 6-10 wk and occasionally results in increased susceptibility to infection or bleeding if the marrow dose exceeds about $2 \mathrm{~Sv}$ (200 rem) (73). A normal pretherapy complete blood count and renal profile make these side effects unlikely. If these blood test results are abnormal, dosimetry is advised to determine the highest safe ${ }^{131} \mathrm{I}$ activity while delivering less than $2 \mathrm{~Sv}$ (200 rem) to the blood and bone marrow (74). 
Oral mucositis with small, painful mouth ulcerations may often be prevented by gentle brushing of the entire oral mucosa with a soft toothbrush about every 3-4 h for 4-7 d while awake; this can be extended to every $3 \mathrm{~h}$ at night for the first $4 \mathrm{~d}$ after treatment. The issue deserves further formal study. Dysgeusia is uncommon, transient, and usually mild, if acute salivary inflammation is avoided.

Uncommon side effects can result from rhTSHinduced edema of metastases in bone (pain), brain or spinal cord (neurologic symptoms), or lung (dyspnea).

Late side effects may include fertility issues. Increases in gonadotropins (serum follicle-stimulating hormone level) and presumably any degree of diminished spermatogenesis are usually transient except in men receiving high therapeutic doses of ${ }^{131} \mathrm{I}$, for whom permanent infertility is possible as administered activities progressively exceed 7.411.1 GBq (200-300 mCi) (75). The level of administered activity above which azoospermia occurs is not clear since infertility has been described in a most unusual patient who received $3.33 \mathrm{GBq}$ (90 mCi) of ${ }^{131}$ I (76). Nevertheless, in one of the largest prospective studies, the radiation dose from a single ablative therapy with ${ }^{131}$ I was well below that associated with permanent damage to the male germinal epithelium, but patients requiring multiple radioiodine administrations may be at higher risk, although no infertility was found in the group studied (77). The radiation dose to the testes can be reduced by frequent voiding. Sperm storage before high-dose ${ }^{131}$ I therapy may be considered, since the posttherapy sperm count may not return to normal when higher doses of ${ }^{131} \mathrm{I}$ are administered. Impairment of female fertility by ${ }^{131}$ I therapy or increased risk of miscarriage has not been described $(78,79)$. The available data are insufficient to suggest a threshold. No effect on birth weight or prematurity in subsequent pregnancies after ${ }^{131} \mathrm{I}$ therapy has been reported $(80)$.

Other late side effects include permanent damage to the salivary glands resulting in xerostomia, sialolithiasis, excessive dental caries, and dysgeusia, and, uncommonly, ${ }^{131}$ I-induced xerophthalmia or epiphora. No threshold for radiation-induced carcinogenesis has been firmly established (81). After high doses of ${ }^{131}$ I therapy, the uncommon development of other malignancies has been reported, including carcinoma of the stomach, bladder, colon, and salivary glands; melanoma; and leukemia $(82,83)$. Reported neoplasms usually occur after more than one therapeutic dose. A causative role for ${ }^{131} \mathrm{I}$ in carcinogenesis, other than for thyroid cancer in children at Chernobyl, is difficult to establish since a small increase over the baseline rate for cancer occurrence in the United States (men, $42 \%$; women, $38 \%$ (84)) would be difficult to detect. During the informed consent process it is important to emphasize to the patient that these late side effects are rarely seen and should not deter the patient from receiving ${ }^{131} \mathrm{I}$ for treatment of thyroid cancer when the benefits of ablation or therapy of metastatic or recurrent cancer clearly outweigh the risks.

Information on pregnancy testing and on breast feeding and lactation is the same as given above for Graves disease, toxic nodules, and nontoxic nodular goiter.

Good hydration of the patient is required (daily, about 2,500-3,000 $\mathrm{mL}$ of any liquid except milk in the average-sized adult patient with normal renal function), with instructions urging frequent (about hourly) urination for several days to a week to reduce radiation exposure to the bladder and salivary glands. For renal insufficiency, the rhTSH dose may be reduced by $50 \%$ or more (85). Hemodialysis is not a contraindication to ${ }^{131} \mathrm{I}$ therapy (32). The patient should have at least one bowel movement a day to reduce colon exposure. Laxatives (but not stool softeners which do not stimulate the bowel) may be necessary in constipated patients.

3. Information required by the physician performing the procedure

The treating physician must obtain the patient's thyroid-related medical history, including all areas in which adverse reactions are possible, and perform a directed physical examination. Pretherapy imaging should be reviewed to aid in determination of the activity to be administered. The cumulative lifetime administered activity of ${ }^{131} \mathrm{I}$ should be reviewed and entered in the patient's record. The operative and, especially, pathology reports should be reviewed, as well as prior images. The patient must not be lactating or nursing.

Information required by the physician regarding the patient's mental status is the same as described above for Graves disease, toxic nodules, and nontoxic nodular goiter.

The treating physician must confirm that appropriate laboratory testing has been performed and must review the results of these tests. The TSH level should be elevated to about $30 \mu \mathrm{IU} / \mathrm{mL}$ before the pretherapy diagnostic scan for those medical centers performing this study or when a pretreatment scan is not performed. Serum thyroglobulin should be obtained, if possible, under TSH suppression and again at the time of maximal TSH stimulation; for rhTSH, this occurs $3 \mathrm{~d}$ after the last rhTSH injection. The postthyroidectomy serum calcium level should be determined to exclude hypoparathyroidism, if not already available. A complete 
blood count should be obtained within about a month of therapy. A renal profile should be obtained within about a month of therapy and a $\beta$-hCG pregnancy test obtained, as described above for Graves disease, toxic nodules, and nontoxic nodular goiter. The patient should not be nauseated before administration of ${ }^{131} \mathrm{I}$.

The authorized user or supervised user (technologist) administering ${ }^{131}$ I should identify the patient and the proper activity of the prescribed radiopharmaceutical according to institutional policy, and the physician should confirm that the patient has not received iodinated contrast medium within the previous 2 mo (86). Any uncertainty may be reduced by measuring urinary iodine excretion.

4. Selection of activity

In general, the greater the risk of metastases or recurrent tumor and the more extensive the invasiveness or dissemination of the cancer at the time of therapy, the higher the ${ }^{131}$ I activity required. In the selection of the administered activity, there are a variety of approaches relating to the risk of cancer recurrence or death, as described above in the definitions section $(3,4)$.

For postoperative ablation of thyroid bed remnants, activity in the range of $1.11-3.7 \mathrm{GBq}(30-$ $100 \mathrm{mCi}$ ) is typically prescribed, depending on the radioiodine uptake measurement and amount of residual functioning tissue present $(87,88)$.

For treatment of thyroid cancer in the cervical or mediastinal lymph nodes, activity in the range of 5.55-7.4 GBq (150-200 mCi) is typically administered. Patients with advanced local or regional disease may be treated first with surgical debulking, then with ${ }^{131}$ I and, if clinically indicated, externalbeam radiation $(89)$.

For treatment of distant metastases, an activity of $7.4 \mathrm{GBq}(200 \mathrm{mCi})$ or more is often given. The radiation dose to the bone marrow is typically the limiting factor. It is recommended that the estimated radiation dose to the bone marrow be less than $2 \mathrm{~Sv}$ (200 rem) (73) Blood and whole-body dosimetry may be indicated when a high activity of ${ }^{131} \mathrm{I}$ is planned to treat metastatic disease $(90,91)$. Dosimetry will determine the maximum safe activity of ${ }^{131} \mathrm{I}$ and is recommended for all such patients over 50-55 y old, especially in the presence of a reduced glomerular filtration rate and when lung metastases may concentrate a large amount of ${ }^{131} \mathrm{I}$ $(92,93)$. To reduce the risk of significant myelosuppression, retention of ${ }^{131} \mathrm{I}$ in the body at $48 \mathrm{~h}$ should be less than $4.44 \mathrm{GBq}(120 \mathrm{mCi})$, or less than 2.96 $\mathrm{GBq}(80 \mathrm{mCi})$ if diffuse lung metastases are present, to reduce the risk of radiation pneumonitis as well. An adaptation of the 2.96-GBq (80-mCi) method has been published to correct for differen- ces in patient size-for example, children versus adults (94).

In the absence of antithyroglobulin antibodies, an elevated or rising serum thyroglobulin level is a useful indicator of residual or recurrent thyroid cancer and may be an indication for empiric radioiodine therapy, using 5.55-7.40 GBq (150-200 mCi) with marrow dosimetry if indicated, even in the absence of discernible activity on the diagnostic radioiodine scan (95). An elevated serum thyroglobulin level does not imply iodine avidity of the tumor. If the thyroglobulin level is elevated but no discernible activity is seen on the diagnostic ${ }^{123} \mathrm{I}$ or ${ }^{131} \mathrm{I}$ scan, thyroid tissue may still be visualized on a posttherapy scan, and the serum thyroglobulin level may fall after empiric ${ }^{131}$ I therapy. However, with continuous TSH suppression, the serum thyroglobulin level may fall even without ${ }^{131} \mathrm{I}$ therapy in some patients. Because there are no double-blind studies demonstrating that recurrence rates and prognosis are altered by empiric ${ }^{131} \mathrm{I}$ therapy under these circumstances, this remains a controversial issue. Risks from radioiodine administration must be weighed against uncertain benefits in this situation, although such empiric ${ }^{131}$ I therapy often causes a decrease in thyroglobulin levels, presumably reflecting a cytocidal effect (96). Besides empiric ${ }^{131} \mathrm{I}$ therapy, surgery is a consideration if focal resectable tumor can be located. Both ${ }^{18}$ F-FDG PET (more sensitive after TSH stimulation) and thyroid ultrasound may be helpful in identifying thyroid cancer metastases when the ${ }^{131}$ I scan findings are negative but the stimulated serum thyroglobulin level is elevated. Older data indicate that when ${ }^{18} \mathrm{~F}$-FDG is unavailable, ${ }^{99 \mathrm{~m}} \mathrm{Tc}$ sestamibi and ${ }^{201} \mathrm{Tl}$ scintigraphy may detect metastatic thyroid cancer with reasonable sensitivity $(53,97)$.

If a level of uptake close to the reference range is observed, further cytoreductive surgery may be advisable to avoid symptomatic radiation thyroiditis and increase the probability of complete ablation. For lower-risk patients with iodine uptake levels in the $8 \%-10 \%$ range, a decrease in administered activity is often sufficient.

Patients whose TSH failed to rise on a withdrawal protocol have been successfully treated with approximately $1.11 \mathrm{GBq}(30 \mathrm{mCi})$ of ${ }^{131} \mathrm{I}$ and retreated later, at about $90 \mathrm{~d}$ when the TSH rose over 30 $\mu \mathrm{IU} / \mathrm{mL}$, with a higher activity. In general ${ }^{131} \mathrm{I}$ therapy is less effective in bulky disease with a diameter greater than 1-2 cm, and surgical excision before radioiodine may yield better results. In renal insufficiency, the rhTSH dose may be reduced by $50 \%$ or more (85). Hemodialysis is not a contraindication to ${ }^{131}$ I therapy (32). 
For children, most pediatric nuclear physicians modify the activity to be administered on a weight basis so that the pediatric activity equals the adult activity that would be given under the same clinical circumstances multiplied by the patient weight in kilograms and divided by 70 . There is no consensus on modifying the dose of rhTSH for children at the time of the writing of this guideline in 2012 .

A short intrathyroidal or body effective ${ }^{131}$ I halflife can be a source of failure of ${ }^{131}$ I therapy in metastatic lesions. Oral administration of lithium carbonate inhibits the liberation of thyroidal thyroxine and thus prolongs the intrathyroidal biologic half-life of administered ${ }^{131} \mathrm{I}$ and occasionally may be useful in patients who have a rapid turnover of radioactive iodine. Serum lithium levels should be monitored to avoid toxicity. There are no doubleblind outcome studies on lithium, and its use adds another layer of complexity to the therapeutic procedure. It is infrequently used at this time $(98,99)$.

5. Therapeutic procedure for administration of ${ }^{131} \mathrm{I}$

The patient should take no food or water by mouth for approximately $2 \mathrm{~h}$ before and after the oral administration of ${ }^{131}$ I. The prophylactic administration of oral antiemetics should be considered before starting ${ }^{131}$ I therapy (except for thyrotoxicosis therapy). The individual administering the ${ }^{131} \mathrm{I}$ should have the signed consent form and, for female patients of child-bearing age, the printed result of the $\beta$-hCG test before giving the patient the radiopharmaceutical. The identity and activity of the radiopharmaceutical to be administered should be documented in writing on the appropriate form. The patient identity should be checked as required by institutional policy. The patient may be provided with a copy of the signed consent form. After
${ }^{131}$ I therapy, the dose rate from the patient at $1 \mathrm{~m}$ should be recorded as required by the relevant regulatory authority or institutional policy. The patient should be informed of any prolongation of the home radiation safety plan if a higher dose rate than anticipated is measured.

6. Follow-up

For staging purposes, patients should undergo whole-body scintigraphy approximately $3-7 \mathrm{~d}$ after treatment. SPECT/CT often has incremental value for staging, patient management, and prediction of the response to ${ }^{131}$ I therapy (100-104). The serum TSH level should be checked about 6$8 \mathrm{wk}$ after treatment to confirm that the level is within the desired therapeutic limits. Since the overall recurrence rate for thyroid cancer approaches $20 \%$, and up to $10 \%$ of recurrences may occur after $20 \mathrm{y}$, long-term follow-up of the patient is required, both to maintain appropriate serum TSH levels and to detect recurrence of disease. The details of clinical follow-up, including TSH suppression, thyroglobulin assessment (suppressed and stimulated), and subsequent imaging, are beyond the scope of this guideline.

\section{Radiation safety issues}

For pregnancy, breast feeding, and lactation, see "Information required by the physician performing the procedure" in section VI, part A.

Regulatory requirements for hospitalization and other radiation protection vary among states and countries, with many guidelines being more stringent than those of the NRC. The NRC has 3 alternate criteria allowing patient release from the hospital after ${ }^{131}$ I therapy:

1. When no individual member of the public is likely to receive more than $5 \mathrm{mSv}$ (500 mrem) from that

TABLE 3

Radiation Absorbed Dose from ${ }^{131}$ I (Nal)

\begin{tabular}{|c|c|c|}
\hline Organ & mGy/MBq & $\mathrm{rad} / \mathrm{mCi}$ \\
\hline \multicolumn{3}{|c|}{ Assuming no thyroid uptake (athyrotic) } \\
\hline Bladder wall & 0.610 & 2.3 \\
\hline Lower colon wall & 0.043 & 0.16 \\
\hline Kidneys & 0.065 & 0.24 \\
\hline Ovaries & 0.042 & 0.16 \\
\hline Testes & 0.037 & 0.14 \\
\hline Stomach & 0.034 & 0.13 \\
\hline \multicolumn{3}{|c|}{ Assuming $55 \%$ thyroid uptake and $20-\mathrm{g}$ gland (hyperthyroid) } \\
\hline Thyroid & 790 & 2.920 \\
\hline Bladder wall & 0.290 & 1.1 \\
\hline Breast & 0.091 & 0.34 \\
\hline Upper colon wall & 0.058 & 0.21 \\
\hline Ovaries & 0.041 & 0.15 \\
\hline Testes & 0.026 & 0.10 \\
\hline
\end{tabular}

Dose may vary depending on whole-body effective half-life of ${ }^{131}$. Data are from ICRP 53 (119). 
TABLE 4

Radiation Dose to Red Marrow for $74-7,400 \mathrm{MBq}$ $(2-200 \mathrm{mCi})^{131}$ I

\begin{tabular}{|c|c|c|c|c|}
\hline \multirow{2}{*}{$\begin{array}{c}\text { Thyroid } \\
\text { uptake (\%) }\end{array}$} & \multicolumn{2}{|c|}{ Adult } & \multicolumn{2}{|c|}{ Child (10 y old) } \\
\hline & mGy/MBq & $\mathrm{rad} / \mathrm{mCi}$ & mGy/MBq & $\mathrm{rad} / \mathrm{mCi}$ \\
\hline 0 & 0.035 & 0.13 & 0.065 & 0.25 \\
\hline 5 & 0.038 & 0.14 & 0.070 & 0.26 \\
\hline 35 & 0.086 & 0.32 & 0.160 & 0.59 \\
\hline 45 & 0.100 & 0.37 & 0.190 & 0.70 \\
\hline 55 & 0.120 & 0.44 & 0.220 & 0.81 \\
\hline
\end{tabular}

Dose may vary depending on whole-body effective half-life of ${ }^{131}$ I. Data are from ICRP 53 (119).

patient, assuming all other regulatory requirements for patient instructions and record keeping are met. NUREG-1556, volume 9, "Consolidated Guidance about Materials Licenses: Program-Specific Guidance about Medical Use Licenses," describes methods for calculating doses to other individuals and contains tables of activities not likely to cause doses exceeding $5 \mathrm{mSv}$ (500 mrem). This guidance is not a regulation. Realistic and scientifically valid, less conservative calculations on patient release, based on the realities of patient life at home, have been published (105-107).

2. When the survey meter reading is less than $0.07 \mathrm{mSv} /$ $\mathrm{h}(7.0 \mathrm{mrem} / \mathrm{h})$ at $1 \mathrm{~m}$. Some radiation meters measure exposure rates in milliroentgens per hour, but for low-linear energy transfer radiation (including $\beta$-particles and most $x$-rays and $\gamma$-rays), the exposure rate at $7 \mathrm{mR} / \mathrm{h}$ will be equivalent to the dose rate at $0.07 \mathrm{mSv} / \mathrm{h}(7 \mathrm{mrem} / \mathrm{h})(108)$.
3. When the administered activity is $1.22 \mathrm{GBq}(33$ $\mathrm{mCi}$ ) or less.

If the patient is to be treated as an inpatient, nursing personnel must be instructed in all relevant radiation safety procedures. Selected nursing personnel should be provided with appropriate radiation monitors (film badge, direct-reading dosimeters, etc.). Nurses who are or may be pregnant are excluded from direct patient care. Any significant medical conditions should be noted and contingency plans made in case radiation precautions must be breached for a medical emergency, as concern about radiation exposure should not interfere with prompt, appropriate medical treatment of the patient should an acute medical problem develop.

Written instructions describing methods to limit the dose to others must be given to the patient if an individual member of the public is likely to receive a radiation dose exceeding $1 \mathrm{mSv}$ (100 mrem) from that patient, and if the administered dosage is greater than $0.26 \mathrm{GBq}(7 \mathrm{mCi})$ (17). Individual Agreement States may have specific rules and regulations regarding the release of patients with significant residual activity. Details on the relevant federal regulations can be obtained at the NRC Web site (www.nrc.gov) or by telephone (301-415-7000).

As a precaution, before releasing the patient the licensee should instruct the patient on how to reduce unnecessary radiation exposure to family members and members of the public. Written instructions must be provided to reduce the radiation dose both to the patient and to members of the public and may be required in some jurisdictions (109). With simple precautions, the radiation dose to family members is

TABLE 5

Red Marrow Dose and Organ Receiving Highest Dose from 131]

\begin{tabular}{|c|c|c|c|c|c|c|}
\hline \multirow[b]{2}{*}{ Patient } & \multirow{2}{*}{$\begin{array}{c}\text { Maximum thyroid } \\
\text { uptake (\%) }\end{array}$} & \multicolumn{3}{|c|}{ Largest radiation dose } & \multicolumn{2}{|c|}{ Red marrow dose } \\
\hline & & Organ & mGy/MBq & $\mathrm{rad} / \mathrm{mCi}$ & mGy/MBq & $\mathrm{rad} / \mathrm{mCi}$ \\
\hline \multirow[t]{7}{*}{ Adult } & 0 & Bladder & 0.61 & 2.3 & 0.035 & 0.13 \\
\hline & 5 & Thyroid & 72 & 270 & 0.038 & 0.14 \\
\hline & 15 & Thyroid & 210 & 780 & 0.054 & 0.20 \\
\hline & 25 & Thyroid & 360 & 1,300 & 0.070 & 0.26 \\
\hline & 35 & Thyroid & 500 & 1,850 & 0.086 & 0.32 \\
\hline & 45 & Thyroid & 640 & 2,400 & 0.10 & 0.37 \\
\hline & 55 & Thyroid & 790 & 2,900 & 0.12 & 0.44 \\
\hline \multirow[t]{7}{*}{ Child (5 y old) } & 0 & Bladder & 1.8 & 6.7 & 0.10 & 0.37 \\
\hline & 5 & Thyroid & 370 & 1,370 & 0.10 & 0.37 \\
\hline & 15 & Thyroid & 1,100 & 4,100 & 0.14 & 0.52 \\
\hline & 25 & Thyroid & 1,900 & 7,000 & 0.18 & 0.67 \\
\hline & 35 & Thyroid & 2,600 & 9,600 & 0.22 & 0.81 \\
\hline & 45 & Thyroid & 3,300 & 12,000 & 0.26 & 0.96 \\
\hline & 55 & Thyroid & 4,100 & 15,000 & 0.29 & 1.1 \\
\hline
\end{tabular}

In situations involving radiation therapy, it is inappropriate to use the quantity "effective dose," as this quantity relates to risk of stochastic effects from low-dose procedure. In this application, dose to red marrow is of more clinical interest, as clinically significant pancytopenia could occur with ${ }^{131}$ I therapy. 
TABLE 6

Dose Estimates to Fetus from ${ }^{131}$ I

\begin{tabular}{lcc}
\hline \multirow{2}{*}{$\begin{array}{c}\text { Stage of } \\
\text { gestation }\end{array}$} & \multicolumn{2}{c}{ Fetal dose } \\
\cline { 2 - 3 } & $\mathrm{mGy} / \mathrm{MBq}$ & $\mathrm{rad} / \mathrm{mCi}$ \\
\hline Early & 0.072 & 0.27 \\
$3 \mathrm{mo}$ & 0.068 & 0.25 \\
$6 \mathrm{mo}$ & 0.23 & 0.85 \\
$9 \mathrm{mo}$ & 0.27 & 1.0
\end{tabular}

Data are from Russell et al. (120). Information about possible placental crossover of this compound was included in the calculations.

low (considerably less than the NRC upper limit of 5 $\mathrm{mSv}$ [500 mrem]) even when patients are not admitted to a hospital (110). In a study where the patients were to sleep alone and avoid prolonged personal contact for $2 \mathrm{~d}$ after therapy, 65 household members received a mean dose of $0.24 \mathrm{mSv}(24 \mathrm{mrem})$ (range, 0.01-1.09 mSv [1-109 mrem]) (111).

The patient must sleep alone and should abstain from intercourse for approximately $1 \mathrm{wk}$ after therapy (a conservative estimate) unless patient-specific calculations, using several assumptions, indicate that this period can be shortened. Pregnant women and children may have about 10 min of zero distance per day from the patient but otherwise should maintain

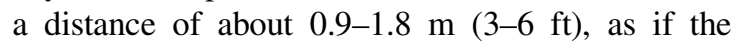
patient had a bad cold. There are no other restrictions on the patient being with other adults. Infants and small children requiring feeding, changes of clothing, and similar care from the treated parent will require another caregiver for up to a week.

There is no hazard to any member of the family arising from sites where the patient sits, what the patient has touched, or what the patient cooks. Internal exposure of family members from items contaminated by patient saliva or urine must be prevented. Although telephone mouthpieces and other devices touched frequently may have minimal ${ }^{131}$ I contamination detected on them, this is not a health hazard because of the minute amount of radiation present compared with ambient background radiation. Disposable plates and utensils are not only unnecessary but, if used, can trigger sensitive waste facility alarms; dishes and utensils should not be shared before washing. It is unnecessary to wash the patient's laundry separately. Patients should flush the toilet twice after use and wash their hands for $20 \mathrm{~s}$. Men should urinate sitting down to avoid contamination in the toilet area. Although certain proprietary products are advertised for specifically decontaminating ${ }^{131} \mathrm{I}$ in the home, such products are not necessary in the typical home situation.
TABLE 7

Estimated Doses to Fetal Thyroid

\begin{tabular}{ccr}
\hline \multirow{2}{*}{$\begin{array}{c}\text { Gestational } \\
\text { age }(\mathrm{mo})\end{array}$} & \begin{tabular}{c} 
Dose from ${ }^{131} \mathrm{I}$ \\
\cline { 2 - 3 } \\
administered to mother
\end{tabular} & $\begin{array}{r}\mathrm{rad} / \\
\mathrm{mCi}\end{array}$ \\
\hline 3 & 230 & 850 \\
4 & 260 & 960 \\
5 & 580 & 2,150 \\
6 & 550 & 2,000 \\
7 & 390 & 1,400 \\
8 & 350 & 1,300 \\
9 & 270 & 1,000 \\
\hline
\end{tabular}

Data (mGy/MBq administered to the mother) are from Watson (121).

Prolonged use of public transportation is discouraged for the first $24 \mathrm{~h}$ after ${ }^{131} \mathrm{I}$ therapy. Although title 10 of Code of Federal Regulations part 35.75 does not expressly prohibit the release of a radioactive patient to a location other than a private residence, such as a hotel, the NRC strongly discourages this practice because it can result in radiation exposure to members of the public for which the licensee may not be able to assess full compliance with title 10 of Code of Federal Regulations part 35.75(a) and may result in doses that are not as low as reasonably achievable (112).

Most experts recommend that both men and women wait 6-12 mo after ${ }^{131}$ I therapy before trying to conceive a child, although there are no reliable data on the validity of this suggested interval. A 12mo interval also allows for follow-up imaging to evaluate the effectiveness of the treatment (113) and for retreatment if deemed appropriate.

Patient-specific calculations of radiation exposure to others can be performed, using several assumptions, and specific recommendations given to each patient about the time and distance to stay away from others. Radiation surveys of the thyroid gland on personnel administering ${ }^{131} \mathrm{I}$ are performed periodically, depending on local regulations and institutional policy. Patients must be provided with a written document stating they have been given a radioactive substance, the date of administration, the name of the radiopharmaceutical, and the activity administered in the event that it is detected by monitoring devices during travel.

\section{Interactions of ${ }^{131}$ I with other forms of diagnosis or treatment}

Patients with advanced local or regional recurrent disease or distant metastases, especially those with involvement of the aerodigestive tract, brain, or spinal cord, may be treated with both ${ }^{131} \mathrm{I}$ and external-beam 
radiation postoperatively. Corticosteroids to prevent swelling may be required if central nervous system metastases are to be irradiated. The use of externalbeam radiation beforehand, or alternating with ${ }^{131} \mathrm{I}$ treatment, has not been documented to be associated with a subsequent reduction in tumor uptake of radioactive iodine. Therefore, external-beam radiation, if clinically and emergently indicated, need not be delayed. The toxicity, acute and late, is likely to be additive within the field of irradiation. Dosimetry calculations are especially important if ${ }^{131}$ I therapy and external-beam radiotherapy are both being considered, or have previously been performed in patients with spinal metastases, to avoid potential radiation-induced spinal cord damage. A treatment planning method for combination external-beam therapy with radiopharmaceutical therapy is available (114).

Skeletal metastases that are painful or are a threat to life or function may, in addition to being treated with ${ }^{131} \mathrm{I}$, be treated with bone-seeking $\beta$-emitting radiopharmaceuticals (e.g., ${ }^{89} \mathrm{Sr}$ or ${ }^{153} \mathrm{Sm}$-lexidronam) if the bone scan is positive at the painful site, although these carry a greater risk of myelosuppression than ${ }^{131}$ I, external radiotherapy, or surgery.

Other scintigraphic studies may be performed a week or more after therapy, but the patient should first be checked under the $\gamma$-camera for residual activity from ${ }^{131}$ I. The posttherapy time when scanning with other radiopharmaceuticals becomes possible will vary with the effective half-life and administered activity of the therapeutic ${ }^{131} \mathrm{I}$.

\section{E. Radiopharmaceuticals}

See section VI for guidance on selection of the administered activity for the treatment of hyperthyroidism and thyroid cancer.

Therapeutic ${ }^{131} \mathrm{I}$ can be administered in liquid or capsule form. If a capsule or a liquid form is used, strategies for minimizing volatilization or inhalation of volatilized iodine during dosage preparation and administration should be used-for example, venting the dose into a filtering system, such as a fume hood, maintaining alkaline $\mathrm{pH}$, and administering the dose to the patient shortly thereafter. Stabilized forms of radioactive iodine, in wide use in the United States, should not require these precautions, which remain a condition of many licenses.

The prescribed activity of ${ }^{131}$ I must be verified, ideally by 2 observers, in a dose calibrator before administration.

All radiopharmaceuticals mentioned in this guideline either should have been approved by the Food and Drug Administration (115) or should follow the SNMMI position statement on the use of compounded preparations and comply with the Medication Management Standards of the Joint Commission.

\section{F. Issues requiring further clarification}

Several issues require further clarification:

1. The utility of routine ${ }^{123} \mathrm{I}$ or ${ }^{131} \mathrm{I}$ whole-body imaging, especially SPECT/CT, in patients after total thyroidectomy before initial ${ }^{131}$ I ablative therapy for thyroid cancer, not only to determine the need for a change in patient management but also to determine whether these preablation and pretherapy imaging techniques lead to better outcomes (e.g., more complete remissions or improved survival).

2. The pathophysiologic and prognostic significance of stunning of the thyroid remnant and metastatic deposits.

3. The diagnostic role of alternative imaging agents for thyroid cancer, such as ${ }^{123} \mathrm{I},{ }^{124} \mathrm{I}$, and ${ }^{99 \mathrm{~m}} \mathrm{Tc}$.

4. The role of ${ }^{124} \mathrm{I}$ in thyroid dosimetry, and the efficacy of lesion dosimetric planning (116-118).

5. The necessity of ${ }^{131} \mathrm{I}$ therapy for low-risk papillary cancers less than $1.0 \mathrm{~cm}$ in diameter if there is an unfavorable molecular assessment (e.g., BRAF expression [a protooncogene encoding a serine/ threonine protein kinase called B-Raf]), unfavorable histology, and no evidence of distant metastases.

6. The equivalence between rhTSH as an adjunct to ${ }^{131}$ I therapy of metastatic thyroid carcinoma and ${ }^{131} \mathrm{I}$ therapy after endogenous TSH elevation from thyroid hormone withdrawal.

7. The frequency and length of long-term followup after ${ }^{131}$ I therapy for thyroid cancer in a variety of clinical situations.

8. Prediction of the time required for the TSH to rise sufficiently in individual patients after thyroid hormone withdrawal before ${ }^{131}$ I therapy.

9. The need to attain a serum TSH level of at least $30 \mu \mathrm{U} / \mathrm{mL}$ before therapy versus lower or higher degrees of elevation.

10. Standardization of ${ }^{131} \mathrm{I}$ dosimetry to deliver a therapeutic dose to hyperfunctioning thyroid glands or ablative radiation doses to thyroid remnants after thyroidectomy.

11. The actual benefits and risks of empiric highactivity ${ }^{131} \mathrm{I}$ therapy (e.g., $>9.25 \mathrm{GBq}[250$ $\mathrm{mCi}]$ ) for patients with serum thyroglobulin elevation but negative iodine scintigraphy results.

12. The therapeutic benefit of administered activities in excess of, for example, $9.25 \mathrm{GBq}(250$ $\mathrm{mCi}$ ), in iodine-avid metastatic disease, relative to lower activities of ${ }^{131} \mathrm{I}$.

13. Determination of whether external-beam radiotherapy delivered to regional neck metastases before therapeutic ${ }^{131}$ I decreases the subsequent ${ }^{131}$ I therapeutic effect.

14. The effectiveness of suggested protocols in preventing radiation sialadenitis and oral mucositis. 


\section{DOCUMENTATION/REPORTING}

For the goals of a nuclear medicine report, see the SNMMI Guideline for General Imaging. For information on direct communication, see the SNMMI Guideline for General Imaging and the ACR Practice Guideline for Communication: Diagnostic Radiology.

The report to the referring physician should include the indication for therapy, the ${ }^{131} \mathrm{I}$ administered activity, a notation that informed consent was obtained (including mention of all possible side effects), the results of a urine or serum pregnancy test, a statement that the patient was informed in writing of home radiation safety precautions, and a notation that travel precautions were discussed and a relevant card or letter provided.

See the SNMMI Guideline for General Imaging for the content of each section of the report: study identification, patient demographics, clinical information, procedure description, description of therapeutic administration including premedication details, mention of absence of pregnancy and lactation in women of childbearing age, recommendations for follow-up, and comments.

\section{EQUIPMENT SPECIFICATION}

See the SNMMI Guideline for General Imaging.

\section{QUALITY CONTROL AND IMPROVEMENT}

See the SNMMI Guideline for General Imaging.

\section{SAFETY, INFECTION CONTROL, AND PATIENT EDUCATION CONCERNS}

See the SNMMI Guideline for General Imaging.

\section{RADIATION DOSIMETRY}

See also the SNMMI Guideline for General Imaging. Radiation dosimetry data are presented in Tables 3-7.

It is the position of the SNMMI that patient exposure to ionizing radiation should be at the minimum level consistent with obtaining a diagnostic examination or performing effective therapeutic procedures. Patient radiation exposure may be reduced by administering a lower dose of radiopharmaceutical when the clinical situation and technique or equipment used for imaging can support such an action. Each patient procedure is unique, and the methodology to achieve minimum exposure while maintaining diagnostic accuracy and therapeutic efficacy needs to be viewed in this light. The radiopharmaceutical dose ranges outlined in this document should be considered a guide. Dose reduction techniques should be used when appropriate. The same principles should be applied when CT is used in a hybrid imaging procedure. CT acquisition protocols should be optimized to provide the information needed while minimizing patient radiation exposure. Minimizing radiation dose is especially important in children, and exposure to the public is always a consideration (111). See also the infor- mation on follow-up of ${ }^{131} \mathrm{I}$ therapy of thyroid cancer in section VI above.

Other special cases of dosimetry for the potentially pregnant patient, including dosimetry for hyperthyroid patients, athyreotic patients, and the unique case in which conception occurs some days or weeks after administration of ${ }^{131} \mathrm{I}$, can be found on the RADAR Web site (http://www. doseinfo-radar.com/RADAR-INT-NM.html) under the heading "The Pregnant Patient."

\section{ACKNOWLEDGMENTS}

The Committee on SNMMI Guidelines consists of the following individuals: Kevin J. Donohoe, MD (Chair) (Beth Israel Deaconess Medical Center, Boston, MA); Sue Abreu, MD (Sue Abreu Consulting, Nichols Hills, OK); Helena Balon, MD (William Beaumont Hospital, Royal Oak, MI); Twyla Bartel, DO (UAMS, Little Rock, AR); Paul E. Christian, CNMT, BS, PET (Huntsman Cancer Institute, University of Utah, Salt Lake City, UT); Dominique Delbeke, MD (Vanderbilt University Medical Center, Nashville, TN); Vasken Dilsizian, MD (University of Maryland Medical Center, Baltimore, MD); Kent Friedman, MD (NYU School of Medicine, New York, NY); James R. Galt, PhD (Emory University Hospital, Atlanta, GA); Jay A. Harolds, MD (OUHSC-Department of Radiologic Science, Edmond, OK); Aaron Jessop, MD (UT MD Anderson Cancer Center, Houston, TX); David H. Lewis, MD (Harborview Medical Center, Seattle, WA); J. Anthony Parker, MD, PhD (Beth Israel Deaconess Medical Center, Boston, MA); James A. Ponto, RPh, BCNP (University of Iowa Hospitals and Clinics, Iowa City, IA); Lynn T. Roy, CNMT (Cedars-Sinai Medical Center, Los Angeles, CA); Heiko Schoder, MD (Memorial Sloan-Kettering Cancer Center, New York, NY); Barry L. Shulkin, MD, MBA (St. Jude Children's Research Hospital, Memphis, TN); Michael G. Stabin, PhD (Vanderbilt University, Nashville, TN); and Mark Tulchinsky, MD (Milton S. Hershey Medical Center, Hershey, PA)

\section{REFERENCES}

1. Stopping Power for Electrons and Positrons. Bethesda, MD: ICRU; 1984:206. Report 37.

2. Eckerman KF, Endo A. MIRD: Radionuclide Data and Decay Schemes. Reston, VA: Society of Nuclear Medicine and Molecular Imaging; 2008.

3. Sacks W, Fung CH, Chang JT, Waxman A, Braunstein GD. The effectiveness of radioactive iodine for treatment of low risk thyroid cancer: a systematic analysis of the peer-reviewed literature from 1966 to April 2008. Thyroid. 2010;20: 1235-1245.

4. Cooper DS, Doherty GM, Haugen BR, et al. Revised American Thyroid Association management guidelines for patients with thyroid nodules and differentiated thyroid cancer. Thyroid. 2009;19:1167-1214.

5. Edge SB, Byrd DR, Compton CC, Fritz AG, Greene FL, Trotti A, eds. AJCC Cancer Staging Manual. 7th ed., New York, NY: Springer; 2009:87-96.

6. Mazzaferri EL. Managing small thyroid cancers. JAMA. 2006;295:2179-2182.

7. Hay ID, Bergstralh EJ, Goellner JR, Ebersold JR, Grant CS. Predicting outcome in papillary thyroid cancer: development of a reliable prognostic scoring system in a cohort of 1779 patients surgically treated at one institution during 1940 through 1989. Surgery. 1993;114:1050-1058. 
8. Hermus AR, Huysmans DAKC. Treatment of benign nodular thyroid disease. $N$ Engl J Med. 1998;338:1438-1447.

9. Huysmans DAKC, Hermus ARMM, Corstens FH, Berentsz JC, Kloppenborg PW. Large compressive goiters treated with radioiodine. Ann Intern Med. 1994;121: 757-762.

10. Bonnema SJ, Bertelsen H, Mortensen J, et al. The feasibility of high dose iodine-131 treatment as an alternative to surgery in patients with a very large goiter: effect of thyroid function and size and pulmonary function. $J$ Clin Endocrinol Metab. 1999;84:3636-3641.

11. Conjoint statement of the SNM, ACNM, and ABNM on credentialing and delineation of privileges for therapeutic procedures using radiopharmaceuticals. J Nucl Med. 2011;52:323-326.

12. ACGME Program Requirements for Graduate Medical Education in Nuclear Medicine. Chicago, IL: ACGME; July 1, 2011.

13. Werner MC, Romaldini JH, Bomberg N, et al. Adverse effects related to thionamide drugs and their dose regimen. Am J Med Sci. 1989;297:216-219.

14. Andrade VA, Gross JL, Maia AL. The effect of methimazole pretreatment on the efficacy of radioiodine therapy in Graves' hyperthyroidism: one-year follow-up of a prospective, randomized study. J Clin Endocrinol Metab. 2001;86:3488-3493.

15. Alexander EK, Larsen PR. High dose ${ }^{131} \mathrm{I}$ therapy for the treatment of hyperthyroidism caused by Graves' disease. J Clin Endocrinol Metab. 2002;87:10731077.

16. Braga M, Walpert N, Burch HB, Solomon BL, Cooper DS. The effect of methimazole on cure rates after radioiodine treatment of Graves' hyperthyroidism: a randomized clinical trial. Thyroid. 2002;12:135-139.

17. Release of individuals containing unsealed byproduct material or implants containing byproduct material. Title 10 of Code of Federal Regulations part 35.75.

18. Ponto KA, Zang S, Kahaly GJ. The tale of radioiodine and Graves' orbitopathy. Thyroid. 2010;20:785-793.

19. Ron E, Doody MM, Becker DV, et al. Cancer mortality following treatment for adult hyperthyroidism. Cooperative Thyrotoxicosis Therapy Follow-up Study Group. JAMA. 1998;280:347-355.

20. Graham GD, Burman KD. Radioiodine treatment of Graves' disease: an assessment of its potential risks. Ann Intern Med. 1986;105:900-905.

21. Braverman L, Kloos RT, Law B Jr, Kipnes M, Dionne M, Magner J. Evaluation of various doses of recombinant human thyrotropin in patients with multinodular goiters. Endocr Pract. 2008;14:832-839.

22. Ceccarelli C, Antonangeli L, Bozzi F, et al. Radioiodine ${ }^{131}$ I treatment for large nodular goiter: recombinant human thyrotropin allows the reduction of radioiodine ${ }^{131} \mathrm{I}$ activity to be administered in patients with low uptake. Thyroid. 2011;21:759-764.

23. Schneider PB. Simple, rapid thyroid function testing with ${ }^{99 \mathrm{~m}} \mathrm{Tc}$ pertechnetate thyroid uptake ratio and neck/thigh ratio. AJR. 1979;132:249-253.

24. Maisey MN, Natarajan TK, Hurley P, Wagner HN. Validation of a rapid computerized method of measuring ${ }^{99 \mathrm{~m}} \mathrm{Tc}$-pertechnetate uptake for routine assessment of thyroid structure and function. J Clin Endocrinol Metab. 1973;36:317-322.

25. Bahn RS, Burch HB, Cooper DS, et al. Hyperthyroidism and other causes of thyrotoxicosis: management guidelines of the American Thyroid Association and American Association of Endocrinologists. Endocr Pract. 2011;17:456-520.

26. Burrow GN, Fisher DA, Larsen PR. Maternal and fetal thyroid function. N Engl J Med. 1994;331:1072-1078.

27. Tran P, Desimone S, Barrett M, Bachrach B. I-131 treatment of Graves' disease in an unsuspected first trimester pregnancy: the potential for adverse effects on the fetus and a review of the current guidelines for pregnancy screening. Int $J$ Pediatr Endocrinol. March 14, 2010 [Epub ahead of print].

28. Brzozowska M, Roach PJ. Timing and potential role of diagnostic I-123 scintigraphy in assessing radioiodine breast uptake before ablation in postpartum women with thyroid cancer. Clin Nucl Med. 2006;31:683-687.

29. Stabin MG, Blackwell R, Brent RL, et al. Fetal Radiation Dose Calculations. Washington, DC: American National Standards Institute; 2008. ANSI N13.542008.

30. Stabin MG, Breitz H. Breast milk excretion of radiopharmaceuticals: mechanisms, findings, and radiation dosimetry. J Nucl Med. 2000;41:863-873.

31. Hsiao E, Huynh T, Mansberg R, Bautovich R, Roach P. Diagnostic I-123 scintigraphy to assess potential breast uptake of I-131 before radioiodine therapy in a postpartum woman with thyroid cancer. Clin Nucl Med. 2004;29:498-501.

32. Holst JP, Burman KD, Atkins F, Umans JG, Jonklaas J. Radioiodine therapy for thyroid cancer and hyperthyroidism in patients with end-stage renal disease on hemodialysis. Thyroid. 2005;15:1321-1331.

33. Leslie WD, Ward L, Salamon EA, et al. A randomized comparison of radioiodine doses in Graves' hyperthyroidism. J Clin Endocrinol Metab. 2003;88:978-983.
34. Reinhardt MJ, Brink I, Joe AY, et al. Radioiodine therapy in Graves' disease based on tissue-absorbed dose calculations: effect of pretreatment thyroid volume on the final outcome. Eur J Nucl Med Mol Imaging. 2002;29:1118-1124.

35. Lassmann M, Reiners C, Luster M. Dosimetry and thyroid cancer: the individual dosage of radioiodine. Endocr Relat Cancer. 2010;17:R161-R172.

36. Kobe C, Eschner W, Sudbrock F, et al. Graves' disease and radioiodine therapy: is success of ablation dependent on the achieved dose above 200 Gy? Nuklearmedizin. 2007;47:13-17.

37. Ceccarelli C, Bencivelli W, Vitti P, Grasso L, Pinchera A. Outcome of radioidine131 therapy in hyperfunctioning thyroid nodules: a 20 years' retrospective study. Clin Endocrinol (Oxf). 2005;62:331-335.

38. Ratcliffe GE, Coke S, Fogelman I, Maisey MN. Radioiodine treatment of solitary functioning nodules. Br J Radiol. 1986;59:385-387.

39. Tzvetov G, Hirsch D, Shrago-Slutzky IS, et al. Well-differentiated thyroid carcinoma: comparison of microscopic and macroscopic disease. Thyroid. 2009;19:487-494.

40. Arora N, Turbendian HK, Kato MA, Moo TA, Zarnegar R, Fahey TJ Jr. Papillary thyroid carcinoma and microcarcinoma: is there a need to distinguish the two? Thyroid. 2009;19:473-477.

41. Pazaitou-Panayiotou K, Capezzone M, Pacini F. Clinical features and therapeutic implications of papillary thyroid microcarcinoma. Thyroid. 2007;17:10851092.

42. So YK, Son YI, Hong SD, et al. Subclinical lymph node metastasis in papillary thyroid microcarcinoma: a study of 551 resections. Surgery. 2010;148:526-531.

43. Jonklaas J, Sarlis NJ, Litofsky D, et al. Outcomes of patients with differentiated thyroid carcinoma following initial therapy. Thyroid. 2006;16:1229-1242.

44. Blum M, Tiu S, Chu M, et al. I-131 SPECT/CT elucidates cryptic findings on planar whole-body scans and can reduce needless therapy with I-131 in post thyroidectomy thyroid cancer patients. Thyroid. 2011;21:1235-1247.

45. Van Nostrand D, Aiken M, Atkins F, et al. The utility of radioiodine scans prior to iodine-131 ablation in patients with well-differentiated thyroid cancer. Thyroid. 2009; 19:849-855.

46. Wong KK, Zarzhevsky N, Cahill JM, et al. Hybrid SPECT-CT and PET-CT imaging of differentiated thyroid carcinoma. Br J Radiol. 2009;82:860-876.

47. Wong KK, Frey KA, Koral KF, et al. Staging of differentiated thyroid carcinoma using diagnostic ${ }^{131}$ I SPECT-CT. AJR. 2010;195:730-736.

48. Datz FL. Cerebral edema following iodine-131 therapy for thyroid carcinoma metastatic to the brain. J Nucl Med. 1986;27:637-640.

49. Goffman T, Ioffe V, Tuttle M. Near-lethal respiratory failure after recombinant human thyroid-stimulating hormone use in a patient with metastatic thyroid cancer. Thyroid. 2003;13:827-830.

50. Silberstein EB. Comparison of outcomes after ${ }^{123} \mathrm{I}$ versus ${ }^{131} \mathrm{I}$ preablation imaging before radioiodine ablation in differentiated thyroid carcinoma. $J \mathrm{Nucl}$ Med. 2007;48:1043-1046.

51. Hilditch TE, Dempsey MF, Bolster AA, McMenemin RM, Reed NM. Selfstunning in thyroid ablation: evidence from comparative studies of diagnostic ${ }^{131}$ I and ${ }^{123}$ I. Eur J Nucl Med Mol Imaging. 2002;29:783-788.

52. Morris LF, Waxman AD, Braunstein GD. The nonimpact of thyroid stunning: remnant ablation rates in I-131-scanned and nonscanned individuals. J Clin Endocrinol Metab. 2001;86:3507-3511.

53. Alam MS, Takeuchi R, Kasagi K, et al. Value of combined technetium-99m hydroxyl methylene diphosphonate and thallium-201 imaging in detecting bone metastases from thyroid carcinoma. Thyroid. 1997;7:705-712.

54. Ito S, Kato K, Ikeda M, et al. Comparison of ${ }^{18} \mathrm{~F}-\mathrm{FDG}$ PET and bone scintigraphy in detection of bone metastases of thyroid cancer. J Nucl Med. 2007; 48:889-895.

55. Schirrmeister H, Buck A, Guhlman A, Reske SN. Anatomical distribution and sclerotic activity of bone metastases from thyroid cancer assessed with F-18 sodium fluoride positron emission tomography. Thyroid. 2001;11:677-683.

56. Wang W, Macapinlac H, Larson SM, et al. [ $\left.{ }^{18} \mathrm{~F}\right]-2$-fluoro-2-deoxy-D-glucose positron emission tomography localizes residual thyroid cancer in patients with negative diagnostic ${ }^{131} \mathrm{I}$ whole body scans and elevated thyroglobulin levels. J Clin Endocrinol Metab. 1999;84:2291-2302.

57. Robbins RJ, Larson SM. The value of positron emission tomography (PET) in the management of patients with thyroid cancer. Best Pract Res Clin Endocrinol Metab. 2008;22:1047-1059.

58. Abraham T, Schoder H. Thyroid cancer: indications and opportunities for positron emission tomography/computed tomography imaging. Semin Nucl Med. 2011;41:121-138.

59. Freudenberg LS, Jentzen W, Petrich T, et al. Lesion dose in differentiated thyroid carcinoma metastases after rhTSH or thyroid hormone withdrawal: ${ }^{124}$ I PET/CT dosimetric comparisons. Eur J Nucl Med Mol Imaging. 2010;37: 2267-2276. 
60. Pluijmen MJ, Eustatia-Rutten C, Goslings BM, et al. Effects of low-iodide diet on postsurgical radioiodide ablation therapy in patients with differentiated thyroid carcinoma. Clin Endocrinol (Oxf). 2003;58:428-435.

61. Grigsby PW, Siegel BA, Bekker S, Clutter WE, Moley JF. Preparation of patients with thyroid cancer for ${ }^{131} \mathrm{I}$ scintigraphy or therapy by 1-3 weeks of thyroxine discontinuation. J Nucl Med. 2004;45:567-570.

62. Radioactive iodine (RAI). ThyCa: Thyroid Cancer Survivors Association Web site. Available at: http://www.thyca.org/rai.htm. Accessed February 8, 2012.

63. Matovic MD, Jankovic SM, Jeremic M, Tasic Z, Vlakjovic M. Unexpected effect of furosemide on radioiodine urinary excretion in patients with differentiated thyroid carcinomas treated with iodine-131. Thyroid. 2009;19:843-848.

64. Pacini F, Schlumberger M, Dralle H, Elisei R, Smot JW, Wiersinga W. European consensus for the management of patients with differentiated thyroid carcinoma of the follicular epithelium. Eur J Endocrinol. 2006;154: 787-803.

65. Berg G, Lindstedt G, Suurkula M, Jansson S. Radioiodine ablation and therapy in differentiated thyroid cancer under stimulation with recombinant human thyroid stimulating hormone. J Endocrinol Invest. 2002;25:44-52.

66. Robbins RJ, Larson SM, Sinha N, et al. A retrospective review of the effectiveness of recombinant human TSH as a preparation for radioiodine thyroid remnant ablation. J Nucl Med. 2002;43:1482-1488.

67. Tuttle RM, Brokhin M, Omry G, et al. Recombinant human TSH-assisted radioactive iodine remnant ablation achieves short-term clinical recurrence rates similar to those of traditional thyroid hormone withdrawal. J Nucl Med. 2008;49:764-770.

68. Tala H, Robbins R, Fagin JA, et al. Five-year survival is similar in thyroid cancer patients with distant metastases prepared for radioactive iodine therapy with either thyroid hormone withdrawal or recombinant human TShH. J Clin Endocrinol Metab. 2011;96:2105-2111.

69. Mandel SJ, Mandel L. Radioactive iodine and the salivary glands. Thyroid. 2003;13:265-271.

70. Ma C, Xie J, Jiang Z, et al. Does amifostine have radioprotective effects on the salivary glands in high-dose radioactive iodine-treated differentiated thyroid cancer? Eur J Nucl Med Mol Imaging. 2010;37:1778-1785.

71. Silberstein EB. Reducing the risk of ${ }^{131}$ I-induced-sialadenitis: the role of pilocarpine. J Nucl Med. 2008;49:546-549.

72. Nakada K, Ishibashi T, Takei T, et al. Does lemon candy decrease salivary gland damage after radioiodine therapy for thyroid cancer? J Nucl Med. 2005;46:261266.

73. Drouet M, Herodin F. Radiation victim management and the hematologist in the future: time to revisit therapeutic guidelines? Int J Radiat Biol. 2010;86:636648.

74. Benua RS, Cicale NR, Sonenberg M, et al. The relation of radioiodine dosimetry to results and complications in the treatment of metastatic thyroid cancer. AJR. 1962;87:171-182.

75. Rosário PW, Barroso AL, Rezende LL, et al. Testicular function after radioiodine therapy in patients with thyroid cancer. Thyroid. 2006;16:667-670.

76. Dottorini ME, Vignati A, Mazzucchelli L, Lomuscio G, Colombo L. Differentiated thyroid carcinoma in children and adolescents: a 37 year experience in 85 patients. J Nucl Med. 1997;38:669-675.

77. Hyer S, Vini L, O'Connell M, Pratt B, Harmer C. Testicular dose and fertility in men following I(131) therapy for thyroid cancer. Clin Endocrinol (Oxf). 2002; 56:755-758.

78. Esfahani AF, Eftekhari M, Zenooz N, Saghari M. Gonadal function in patients with differentiated thyroid cancer treated with ${ }^{131}$ I. Hell J Nucl Med. 2004;7: $52-55$.

79. Smith MB, Xue H, Takahashi H, Cangir A, Andrassy RJ. Iodine 131 thyroid ablation in female children and adolescents; long-term risk of infertility and birth defects. Ann Surg Oncol. 1994;1:128-131.

80. Dottorini ME, Lomuscio G, Mazzucchelli L, Vignati A, Colombo L. Assessment of female fertility and carcinogenesis after iodine-131 therapy for differentiated thyroid carcinoma. J Nucl Med. 1995;36:21-27.

81. Health Risks from Exposure to Low Levels of Ionizing Radiation: BEIR VII, Phase 2. Chapter 12. Washington, DC: The National Academies Press; 2006.

82. Brown AP, Chen J, Hitchcock YJ, Szabo A, Shrieve DC, Tward JD. The risk of second primary malignancies up to three decades after the treatment of differentiated thyroid cancer. J Clin Endocrinol Metab. 2008;93:504-515.

83. Sandeep TC, Strachan MWJ, Reynolds RM, et al. Second primary cancers in thyroid cancer patients: a multinational record linkage study. J Clin Endocrinol Metab. 2006;91:1819-1825.

84. U.S. National Cancer Institute Surveillance, Epidemiology, and End Results (SEER) Database, 2005-2007.
85. Pitoia F, Ilera V, Zanchetta MB. Optimum recombinant human thyrotropin dose in patients with differentiated thyroid carcinoma and end stage renal disease. Endocr Pract. 2008;14:961-966.

86. van der Molen AJ, Thomsen HS, Morcos SK. Effect of iodinated contrast media on thyroid function in adults. Contrast Media Safety Committee, European Society of Urogenital Radiology. Eur Radiol. 2004;14:902-907.

87. Johansen K, Woodhouse NJY, Odugbesan O. Comparison of $1073 \mathrm{MBq}$ and $3700 \mathrm{MBq}$ in postoperative ablation of residual thyroid tissue in patients with differentiated thyroid cancer. J Nucl Med. 1991;32:252-254.

88. Pilli T, Brianzoni E, Capoccetti F, et al. A comparison of $1850(50 \mathrm{mCi})$ and 3700 $\mathrm{MBq}(100 \mathrm{mCi})$ 131-iodine administered doses for recombinant thyrotropinstimulated postoperative thyroid remnant ablation in differentiated thyroid cancer. J Clin Endocrinol Metab. 2007;92:3542-3546.

89. Kebebew E, Clark OH. Locally advanced differentiated thyroid cancer. Surg Oncol. 2003;12:91-99.

90. Lassmann M, Hanscheid H, Chiesa C, et al. EANM Dosimetry Committee series on standard procedures for pre-therapeutic dosimetry in differentiated thyroid cancer therapy. Eur J Nucl Med Mol Imaging. 2008;35:1405-1412.

91. Thomas SR, Samaratunga RC, Sperling M, et al. Predictive estimate of blood dose from external counting data preceding radioiodine therapy for thyroid cancer. Nucl Med Biol. 1993;20:157-162.

92. Kulkarni K, van Nostrand D, Atkins F, Aiken M, Burman K, Wartofsky L. The relative frequency in which empiric dosages of radioiodine would potentially overtreat or undertreat patients who have metastatic well-differentiated thyroid cancer. Thyroid. 2006;16:1019-1023.

93. Tuttle RM, Leboeuf R, Robbins RJ, et al. Empiric radioactive iodine dosing regimens frequently exceed maximum tolerated activity levels in elderly patients with thyroid cancer. $J$ Nucl Med. 2006;47:1587-1591.

94. Sgouros G, Song H, Ladenson PW, et al. Lung toxicity in radioiodine therapy of thyroid carcinoma: development of a dose-rate method and dosimetric implications of the 80-mCi rule. J Nucl Med. 2006;47:1977-1984.

95. Silberstein EB. The problem of the patient with thyroglobulin elevation but negative iodine scintigraphy: the TENIS syndrome. Semin Nucl Med. 2011;41: 113-120.

96. Fatourechi V, Hay ID, Javedan H, Wiseman GA, Mullen BP, Gorman CA. Lack of impact of radioiodine therapy in Tg-positive, diagnostic whole body scan-negative patients with follicular cell-derived thyroid cancer. J Clin Endocrinol Metab. 2002;87:1521-1526.

97. Seabold JE, Gurli N, Schurrer M, Atkay R, Kirchner PT. Comparison of ${ }^{99 \mathrm{~m} T c-}$ methoxybutyl isonitrile and ${ }^{201} \mathrm{Tl}$ scintigraphy for detection of residual thyroid cancer after ${ }^{13 I}$ I ablative therapy. J Nucl Med. 1999;40:1434-1440.

98. Pons F, Carrio I, Estorch M, Ginjuame M, Pons J, Milian R. Lithium as an adjuvant of iodine-131 uptake when treating patients with well-differentiated thyroid carcinoma. Clin Nucl Med. 1987;12:644-647.

99. Koong SS, Reynolds JC, Movius EG, et al. Lithium as a potential adjuvant to ${ }^{131}$ I therapy of metastatic well differentiated thyroid carcinoma. J Clin Endocrinol Metab. 1999;84:912-916.

100. Aide N, Huette N, Rame JP, et al. Clinical relevance of single-photon emission computed tomography/computed tomography of the neck and thorax in postablation ${ }^{131}$ I scintigraphy for thyroid cancer. J Clin Endocrinol Metab. 2009;94: 2075-2084.

101. Chen L, Luo Q, Shen Y, et al. Incremental value of ${ }^{131} \mathrm{I}$ SPECT/CT in the management of patients with differentiated thyroid carcinoma. J Nucl Med. 2008;49:1952-1957.

102. Kohlfuerst S, Igerc I, Lobnig M, et al. Posttherapeutic ${ }^{131}$ I SPECT-CT offers high diagnostic accuracy when the findings on the conventional planar imaging are inconclusive and allows a tailored patient treatment regimen. Eur $\mathrm{J} \mathrm{Nucl}$ Med Mol Imaging. 2009;36:886-893.

103. Schmidt D, Linke R, Uder M, et al. Five months' follow-up of patients with and without iodine-positive lymph node metastases of thyroid carcinoma as disclosed by ${ }^{131} \mathrm{I}-\mathrm{SPECT} / \mathrm{CT}$ at first radioablation. Eur J Nucl Med Mol Imaging. 2010;37:699-705.

104. Schmidt D, Szikszai A, Linke R, et al. Impact of ${ }^{131}$ I SPECT/spiral CT on nodal staging of differentiated thyroid carcinoma at the first radioablation. $\mathrm{J} \mathrm{Nucl}$ Med. 2009;50:18-23.

105. Siegel JA, Marcus CS, Stabin MG. Licensee over-reliance on conservatisms in NRC guidance regarding the release of patients treated with ${ }^{131}$ I. Health Phys. 2007;93:667-677.

106. RADAR medical procedure radiation dose calculator and consent language generator. RADAR - the RAdiation Dose Assessment Resource Web site. Available at: http://www.doseinfo-radar.com/RADARDoseRiskCalc.html. Accessed February 8, 2012.

107. Siegel J. Guide for Diagnostic Nuclear Medicine and Radiopharmaceutical Therapy. Reston, VA: Society of Nuclear Medicine; 2004 
108. Consolidated guidance about materials licenses: program-specific guidance about medical use licenses (NUREG-1556, volume 9, revision 2, appendix U, table U.1). United States Nuclear Regulatory Commission Web site. Available at: http://www. nrc.gov/reading-rm/doc-collections/nuregs/staff/sr1556/v9/r2/sr1556v9r2-finalappendices-i-w.pdf. Published January 2008. Accessed February 8, 2012.

109. St. Germain J, Silberstein EB, Vetter RJ, et al. NCRP Report No. 155: Management of Radionuclide Therapy Patients. Bethesda, MD: National Council on Radiation Protection and Measurements; 2006.

110. Zanzonico PB. Radiation dose to patients and relatives incident to ${ }^{131} \mathrm{I}$ therapy. Thyroid. 1997;7:199-204.

111. Grigsby PW, Siegel BA, Baker S, Eichling JO. Radiation exposure from outpatient radioactive iodine (I-131) therapy for thyroid carcinoma. JAMA. 2000;283:2272-2274.

112. NRC Policy on Release of Iodine-131 Therapy Patients Under 10 CFR 35.75 to Locations Other Than Private Residences. Rockville, MD: Nuclear Regulatory Commission; January 25, 2011.

113. Garsi J-P, Schlumberger M, Rubino C, et al. Therapeutic administration of ${ }^{131} \mathrm{I}$ for differentiated thyroid cancer: radiation dose to the ovaries and outcome of pregnancies. J Nucl Med. 2008;49:845-852.

114. Hobbs RF, McNutt T, Baechler S, et al. A treatment planning method for sequentially combining radiopharmaceutical therapy and external radiation therapy. Int J Radiat Oncol Biol Phys. 2011;80:1256-1262.

115. Compliance Policy Guides, section 460.200, Pharmacy Compounding. U.S. Food and Drug Administration Web site. Available at: http://www.fda.gov/ ICECI/ComplianceManuals/CompliancePolicyGuidanceManual/ucm074398. htm. Published March 16, 1992. Reissued May 29, 2002. Accessed February 9, 2012.
116. Flux GD, Haq M, Chittenden SJ, et al. A dose-effect correlation for radioiodine ablation in differentiated thyroid cancer. Eur J Nucl Med Mol Imaging. 2010; 37:270-275.

117. Van Nostrand D, Moreau S, Bandaru VV, et al. ${ }^{124}$ I positron emission tomography versus ${ }^{131} \mathrm{I}$ planar imaging in the identification of residual thyroid tissue and/or metastasis in patients who have well-differentiated thyroid cancer. Thyroid. 2010;20:879-883.

118. Nagarajah J, Jentzen W, Hartung V, et al. Diagnosis and dosimetry in differentiated thyroid carcinoma using ${ }^{124} \mathrm{I}$ PET: comparison of PET/MRI vs. PET/CT of the neck. Eur J Nucl Med Mol Imaging. 2011;38:1862-1868.

119. ICRP publication 53: radiation dose to patients from radiopharmaceuticals. Ann ICRP. 1988;18:275-278.

120. Russell JR, Stabin MG, Sparks RB, Watson EE. Radiation absorbed dose to the embryo/fetus from radiopharmaceuticals. Health Phys. 1997;73:756769.

121. Watson EE. Radiation absorbed dose to the human fetal thyroid. In: Fifth International Radiopharmaceutical Dosimetry Symposium. Oak Ridge, Tennessee: Oak Ridge Associated Universities; 1992:179-187.

\section{APPROVAL}

This practice guideline (version 3.0) was approved by the Board of Directors of the SNMMI on June 8, 2012. Version 1.0 was approved on January 7, 2002, and version 2.0 on September 8, 2005. 